\title{
Taxonomy of Bordetella and Related Organisms of the Families Achromobacteraceae, Brucellaceae, and Neisseriaceae
}

\author{
R. JOHNSON and P. H. A. SNEATH \\ Computer Trials Laboratory, Central Public Health Laboratory, Colindale, London N.W.9, England, \\ and Medical Research Council Microbial Systematics Unit, University of Leicester, \\ Leicester, England
}

\begin{abstract}
A numerical taxonomic study was made of strains belonging to the genera Bordetella, Alcaligenes, Brucella, Acinetobacter, Moraxella, Neisseria, Haemophilus, Actinobacillus, and Pasteurella, together with a few strains from allied genera. They were examined for 139 characters covering a wide range of tests and properties. The strains fell into two major groups. Group A contained Haemophilus, Actinobacillus, and Pasteurella. Group B contained eight main clusters, representing, respectively, Bordetella pertussis, Bordetella parapertussis, Bordetella bronchiseptica combined with Alcaligenes faecalis, Brucella, Acinetobacter anitratus, Acinetobacter lwoffii, and two clusters containing Moraxella and Neisseria strains. Brucella and the three clusters of Bordetella (including Alcaligenes) were more similar to one another than to the other clusters; it is suggested that the family Brucellaceae should comprise these three genera, and that the other genera should be placed elsewhere.
\end{abstract}

Several families of bacteria listed in Bergey's Manual (13) represent aggregations of genera which at best can only be described as loose associations. Instead of encompassing organisms which overall are closely similar, they have been set up to accommodate genera with one or two prominent characters in common. Such a group is Brucellaceae, or its predecessor Parvobacteriaceae $(12,63)$. This family is the niche for those gram-negative, rod-shaped bacteria which require rich media for growth and are responsible for many human and animal infections. Their potential pathogenicity and the alleged difficulties of working with them account largely for their neglect by taxonomists. They tend to grow poorly or to die out on the usual media, whereas the addition of blood to increase growth often interferes with tests.

Within Brucellaceae the genus Bordetella Moreno-López 1952 has been one of the least studied. Three species are generally recognized: the type species $B$. pertussis (the whoopingcough bacillus), B. parapertussis, and B. bronchiseptica. Although these organisms have been placed in various genera (e.g., Haemophilus), in recent years their segregation as a separate genus has become generally accepted $(13,84)$. They do not require $\mathrm{X}$ factor (haematin) or $\mathrm{V}$ factor (nicotinamide adenine dinucleotide) as do species of Haemophilus. The only reason that $B$. pertussis requires blood is to remove toxic substances from growth media; the blood can be replaced by starch or charcoal (65) or by anionic-exchange resins (45).

Bordetella. species are obligate aerobes, whereas species of Haemophilus are facultative anaerobes. The guanine plus cytosine $(\mathrm{G}+\mathrm{C})$ ratios also differ, being 67 to $70 \%$ for Bordetella and 38 to $42 \%$ for Haemophilus $(20,36$, and findings reported below).

The separation of Bordetella from Alcaligenes, Acinetobacter, and Brucella is more difficult to justify, and the main motive for the present work was to investigate this question. Many workers have noted points of similarity between Bordetella bronchiseptica and Alcaligenes faecalis in particular, although they differ somewhat in $\mathrm{G} / \mathrm{C}$ ratio (20). There have been suggestions $(9,10,83)$ that Bordetella bronchiseptica should be placed in either the genus Brucella or Alcaligenes whereas Steel and Cowan (76) considered that Bordetella parapertussis should be included in Acinetobacter. However, there has not been any convincing evidence on these relationships from either serological or genetic studies. We have therefore 
compared Bordetella with some related organisms chosen from the family Brucellaceae, or from genera in which Bordetella species have been placed from time to time. The main findings, together with details on Bordetella and its close allies, are presented here; detailed findings on the genera Haemophilus, Pasteurella, and Actinobacillus are presented elsewhere (72). The individual strain results are also on record (R. Johnson, Ph.D. thesis, Univ. of Leicester, England, 1972).

\section{MATERIALS AND METHODS}

Bacterial strains. One hundred fifty-six strains were selected for study (Table 1). Thirty-eight additional strains of the genera Haemophilus, Pasteurella, and Actinobacillus were also studied and are reported on elsewhere (72). Type strains listed by Sneath and Skerman (73) and the American Type Culture Collection $(2,3)$ were included as far as possible; about forty recent isolates were also examined.

On receipt, all strains were checked for purity and freeze-dried after the fewest possible number of subcultures. Stock cultures were subcultured twice weekly. A careful watch was kept for rough variation or other change, and if this was seen, or contamination occurred, the stock cultures were discarded and replaced from freeze-dried cultures. Stock cultures were replaced in any event after about 25 transfers.

Media. Three maintenance media were used. Most strains were maintained on serum agar. This contained nutrient broth no. 2 (Oxoid Co.) (25 g), agar no. 1 (Oxoid) $(11 \mathrm{~g})$, nicotinic acid $(20 \mathrm{mg})$, distilled water $(930 \mathrm{ml})$. The $\mathrm{pH}$ was adjusted to 7.2 , and, after autoclaving, the medium was held at $50 \mathrm{C}$ and the following sterile solutions were added: haematin $(0.05 \% \mathrm{wt} / \mathrm{vol})(5 \mathrm{ml})$, nicotinamide adenine dinucleotide (NAD) $(0.05 \% \mathrm{wt} / \mathrm{vol})(5 \mathrm{ml})$, cysteine hydrochloride $(2.5 \% \mathrm{wt} / \mathrm{vol})(10 \mathrm{ml})$, inactivated horse serum no. 5 (Burroughs Wellcome Co.) $(50 \mathrm{ml})$. After careful mixing, the medium was dispensed in petri dishes. It was necessary to add these last four components to many of the media used in this study (to avoid repetition they will be referred to as mixture A). The haematin solution was prepared by the method of Butler (15) and sterilized by autoclaving for $5 \mathrm{~min}$ at $121 \mathrm{C}$. The solutions of NAD and cysteine hydrochloride were sterilized by filtration. Some strains did not grow well on this medium. Haemophilus strains were therefore maintained on heated blood agar (19), and Bordetella pertussis strains were maintained on charcoal blood agar (Oxoid).

Serum agar containing haematin and NAD allowed the growth of all strains except those of Bordetella pertussis, but to insure comparability of tests a basal medium was developed that gave satisfactory growth of all strains. Many tests require media which must be transparent so that color changes or zones of clearing or opacity can be observed. Following the suggestions of Kuwajima, Matsui, and Kishigami (45) and of Sutherland and Wilkinson (78), it was found that addition of an anionic exchange resin gave a satisfactory medium that was both transparent and supported the growth of all strains. The basal medium, designated BM agar, had the following formula: nutrient broth no. 2 (Oxoid) $(20 \mathrm{~g})$, casein hydrolysate (Oxoid) $(5 \mathrm{~g})$, agar no. 1 (Oxoid) $(11 \mathrm{~g})$, nicotinic acid $(20 \mathrm{mg}), \mathrm{KH}_{2} \mathrm{PO}_{4}(0.5 \mathrm{~g}), \mathrm{MgCl}_{2} \cdot 6 \mathrm{H}_{2} \mathrm{O}$ $(0.4 \mathrm{~g}), \mathrm{FeSO}_{4} \cdot 7 \mathrm{H}_{2} \mathrm{O}(10 \mathrm{mg}), \mathrm{CaCl}_{2}(100 \mathrm{mg})$, Dowex 1-X8 (BDH Co.) $(5 \mathrm{~g})$, and distilled water $(930$ $\mathrm{ml}$ ). The medium was adjusted to $\mathrm{pH} 7.2$ and after autoclaving for $15 \mathrm{~min}$ at $121 \mathrm{C}$ was cooled to $50 \mathrm{C}$ before adding mixture $\mathrm{A}$. The complete medium was further cooled to $44 \mathrm{C}$ and carefully mixed before pouring (the agar should set quickly so that the resin remains suspended). BM broth was prepared from the same formula by omitting the agar. The resin must be activated before incorporation into the medium, using the following procedure: $500 \mathrm{~g}$ of Dowex l-X8 (20-50 U.S. mesh) is washed in tap water and then covered with 2 liters of $0.5 \mathrm{M} \mathrm{NaOH}$ for $2 \mathrm{~h}$ with occasional agitation. The resin is then washed repeatedly with distilled water until the $\mathrm{pH}$ of the effluent is below 7.5. The final washing is carried out by packing a glass column with the resin and passing distilled water from a 50-liter tank for about $24 \mathrm{~h}$. Results of tests performed using BM as a basal medium showed very good consistency with the results obtained using conventional media.

Stock cultures and tests for all except eleven strains were incubated at $35 \mathrm{C}$ in a moist atmosphere. The following strains grew poorly at $35 \mathrm{C}$ and were incubated at $25 \mathrm{C}: \mathrm{J} 10, \mathrm{~J} 12, \mathrm{~J} 13, \mathrm{~J} 17, \mathrm{~J} 24, \mathrm{~J} 25, \mathrm{~J} 26$, $\mathrm{J} 28$, J29, and $\mathrm{J} 34$. Test results, unless otherwise stated, were recorded after incubation for 2,5 , and 7 days after inoculation from 48-h-old agar cultures, and unless otherwise stated a definite reaction within 7 days was scored as positive in the computer analysis.

Because good growth of all strains was not obtained on conventional media, many of the usual test methods had to be modified. As a safety precaution, some pathogenic strains had to be tested separately and with a limited range of tests. Consequently, only 84 characters were recorded for the Brucella and Francisella strains instead of the 139 characters recorded for the other strains.

Staining and morphology. Strains were grown on BM agar and examined after 1,3 , and 5 days or 2,3 , and 5 days for the slower-growing cultures. Cell shape and arrangement were studied by the hanging drop technique; heat-fixed films were stained by Kopeloff and Beerman's modification of Gram's method (19) and counterstained with $0.1 \%$ basic fuchsin in $0.5 \%$ aqueous phenol. Colonial morphology was described from 48-h-old cultures on BM agar. Motility was determined from hanging-drop preparations examined daily up to 14 days after incubating cultures in duplicate at 25 and $35 \mathrm{C}$ in Craigie tubes (18) of BM broth containing $0.25 \%$ Davis New Zealand agar.

Cultural properties. Ability to grow anaerobically was determined by inoculating a loopful of 48-h-old broth culture onto BM agar and incubating it in an anaerobic jar containing hydrogen and a catalyst. Growth anaerobically in the presence of nitrate was determined similarly on BM agar containing $0.1 \%$ $(\mathrm{wt} / \mathrm{vol}) \mathrm{KNO}_{3}$. Ability to grow on nutrient agar was determined on blood agar base (Oxoid). Hemolysis of 
TABLE 1. Strains studied

\begin{tabular}{|c|c|c|}
\hline $\begin{array}{l}\text { Strain no. in } \\
\text { present survey }\end{array}$ & Received as & $\begin{array}{l}\text { Source }^{a} \text { and } \\
\text { collection no. }\end{array}$ \\
\hline $\mathrm{J} 1$ & Alcaligenes denitrificans & NCTC $8582^{b}$ \\
\hline $\mathrm{J} 2$ & A. odorans & NCTC $10416^{b}$ \\
\hline $\mathrm{J} 3$ & A. faecalis & NCTC 8764 \\
\hline $\mathrm{J} 4$ & A. faecalis & NCTC 655 \\
\hline J5 & A. faecalis & NCTC 8769 \\
\hline $\mathrm{J} 6$ & A. faecalis & NCIB 8156 \\
\hline J7 & A. faecalis & CCEB 591 \\
\hline J8 & A. viscosus & NCTC 3233 \\
\hline $\mathrm{J} 9$ & A. viscosus & NCIB $8154^{c}$ \\
\hline J10 & A. viscosus & NCIB 8596 \\
\hline J 11 & A. metalcaligenes & NCIB 9018 \\
\hline $\mathrm{J} 12$ & A. metalcaligenes & NCIB 9021 \\
\hline $\mathrm{J} 13$ & A. metalcaligenes & NCIB 8734 \\
\hline $\mathrm{J} 17$ & Agrobacterium tumefaciens & NCPPB 397 \\
\hline J18 & Agrobacterium sp. & MJT ZH1 \\
\hline $\mathrm{J} 23$ & Acinetobacter anitratus & NCTC 8102 \\
\hline $\mathrm{J} 24$ & A. anitratus & ATCC 14290 \\
\hline $\mathrm{J} 25$ & A. calcoaceticus & ATCC $23055^{d}$ \\
\hline J26 & Achromobacter haemolysans & ATCC 17988 \\
\hline $\mathrm{J} 27$ & Acinetobacter lwoffii & NCTC $5866^{e}$ \\
\hline $\mathbf{J} 28$ & Acinetobacter sp. & MJT F4/6/20 \\
\hline J29 & Acinetobacter sp. & Baumann 19 \\
\hline $\mathrm{J} 30$ & Acinetobacter sp. & M.S.U. \\
\hline $\mathbf{J} 31$ & Achromobacter haemolyticus & NCTC $10306^{b}$ \\
\hline & subsp. alcaligenes & \\
\hline $\mathrm{J} 32$ & A. haemolyticus & NCTC $10305^{b}$ \\
\hline J33 & A. citroalkaligenes & NCTC $10307^{b}$ \\
\hline J34 & A. conjunctivae & NCTC $10304^{b}$ \\
\hline J35 & A. mucosus & NCTC $10303^{e}$ \\
\hline $\mathrm{J} 36$ & A. liquefaciens & ATCC 15716 \\
\hline J37 & A. lacticus & NCIB 8208 \\
\hline $\mathrm{J} 38$ & Acinetobacter anitratus & NCIB $9212^{f}$ \\
\hline J39 & A. anitratus & NCIB 9019 \\
\hline $\mathrm{J} 40$ & A. anitratus & NCIB 9301 \\
\hline $\mathrm{J} 41$ & Achromobacter sp. & NCIB 8250 \\
\hline $\mathrm{J} 42$ & Bordetella pertussis & NCTC $9797^{c}$ \\
\hline $\mathrm{J} 43$ & $B$. pertussis & NCTC 8189 \\
\hline $\mathrm{J} 44$ & B. pertussis & NCTC 8631 \\
\hline $\mathrm{J} 45$ & $B$. pertussis & IID $18-323$ phase I. \\
\hline $\mathrm{J} 46$ & $B$. pertussis & IID Tohama phase I. \\
\hline $\mathrm{J} 47$ & B. pertussis & IID Yamapaki phase I. \\
\hline $\mathrm{J} 48$ & B. pertussis & IID Opaki phase I. \\
\hline J49 & B. pertussis & IID Maeno phase I. \\
\hline $\mathbf{J} 50$ & B. pertussis & IID Kawarada phase I. \\
\hline J51 & B. pertussis & IID Tohama phase III. \\
\hline J52 & B. pertussis & IID Sakairi phase III. \\
\hline $\mathrm{J} 53$ & B. pertussis & IID Sugata phase III. \\
\hline J54 & B. parapertussis & NCTC $5952^{d}$ \\
\hline J55 & B. parapertussis & ATCC $15237^{d}$ \\
\hline J56 & B. parapertussis & ATCC $15989^{d}$ \\
\hline J57 & B. parapertussis & ATCC 9305 \\
\hline J58 & $B$. bronchiseptica & MSU \\
\hline J59 & B. bronchiseptica & NCTC $452^{d}$ \\
\hline J60 & B. bronchiseptica & NCTC 8344 \\
\hline J61 & B. bronchiseptica & ATCC 19 \\
\hline $\mathrm{J} 62$ & B. bronchiseptica & ATCC 780 \\
\hline J63 & B. bronchiseptica & ATCC 785 \\
\hline J64 & $B$. bronchiseptica & ATCC 786 \\
\hline $\mathrm{J} 65$ & $B$. bronchiseptica & ATCC 4617 \\
\hline
\end{tabular}


TABLE 1.-Continued

\begin{tabular}{|c|c|c|}
\hline $\begin{array}{l}\text { Strain no. in } \\
\text { present survey }\end{array}$ & Received as & $\begin{array}{l}\text { Source }{ }^{a} \text { and } \\
\text { collection no. }\end{array}$ \\
\hline $\begin{array}{l}\text { J66 } \\
\text { J67 } \\
\text { J68 } \\
\text { J69 } \\
\text { J70 } \\
\text { J71 } \\
\text { J72 } \\
\text { J128 } \\
\text { J129 } \\
\text { J130 } \\
\text { J131 } \\
\text { J132 } \\
\text { J133 } \\
\text { J134 } \\
\text { J136 } \\
\text { J137 } \\
\text { J139 } \\
\text { J140 } \\
\text { J141 } \\
\text { J142 } \\
\text { J143 } \\
\text { J144 } \\
\text { J145 } \\
\text { J146 } \\
\text { J147 } \\
\text { J148 } \\
\text { J149 } \\
\text { J150 } \\
\text { J152 } \\
\text { J153 } \\
\text { J154 } \\
\text { J158 } \\
\text { J159 } \\
\text { J161 } \\
\text { J162 } \\
\text { J165 } \\
\text { J172 } \\
\text { J179 } \\
\text { J180 } \\
\text { J181 } \\
\text { J186 } \\
\text { J187 } \\
\text { J188 } \\
\text { J189 } \\
\text { J190 } \\
\text { J191 } \\
\text { J192 } \\
\text { J193 } \\
\text { J194 } \\
\text { J195 } \\
\text { J196 } \\
\text { J197 } \\
\text { J198 } \\
\text { J199 } \\
\text { J200 } \\
\text { J201 } \\
\text { J202 } \\
\text { J203 }\end{array}$ &  &  \\
\hline
\end{tabular}


TABLE 1.-Continued

\begin{tabular}{|c|c|c|}
\hline $\begin{array}{l}\text { Strain no. in } \\
\text { present survey }\end{array}$ & Received as & $\begin{array}{l}\text { Source }{ }^{a} \text { and } \\
\text { collection no. }\end{array}$ \\
\hline $\begin{array}{l}\mathrm{J} 205 \\
\mathrm{~J} 206 \\
\mathrm{~J} 207 \\
\mathrm{~J} 208 \\
\mathrm{~J} 209 \\
\mathrm{~J} 210 \\
\mathrm{~J} 211 \\
\mathrm{~J} 212 \\
\mathrm{~J} 214 \\
\mathrm{~J} 215 \\
\mathrm{~J} 216 \\
\mathrm{~J} 217 \\
\mathrm{~J} 218 \\
\mathrm{~J} 219 \\
\mathrm{~J} 220 \\
\mathrm{~J} 221 \\
\mathrm{~J} 222 \\
\mathrm{~J} 223 \\
\mathrm{~J} 224 \\
\mathrm{~J} 225 \\
\mathrm{~J} 226 \\
\mathrm{~J} 227 \\
\mathrm{~J} 228 \\
\mathrm{~J} 229 \\
\mathrm{~J} 230 \\
\mathrm{~J} 231 \\
\mathrm{~J} 232 \\
\mathrm{~J} 233 \\
\mathrm{~J} 234 \\
\mathrm{~J} 235 \\
\mathrm{~J} 236 \\
\mathrm{~J} 237 \\
\mathrm{~J} 238 \\
\mathrm{~J} 239 \\
\mathrm{~J} 240 \\
\mathrm{~J} 241 \\
\mathrm{~J} 242 \\
\mathrm{~J} 243 \\
\mathrm{~J} 244\end{array}$ & $\begin{array}{l}\text { B. bronchiseptica } \\
\text { B. bronchiseptica } \\
\text { B. bronchiseptica } \\
\text { B. bronchiseptica } \\
\text { B. bronchiseptica } \\
\text { Yellow pigmented rod } \\
\text { B. parapertussis } \\
\text { B. parapertussis } \\
\text { B. parapertussis } \\
\text { B. parapertusiss } \\
\text { B. parapertussis } \\
\text { B. parapertussis } \\
\text { B. parapertussis } \\
\text { B. parapertussis } \\
\text { B. parapertussis } \\
\text { B. parapertussis } \\
\text { B. parapertussis } \\
\text { B. parapertussis } \\
\text { B. parapertussis } \\
\text { B. parapertussis } \\
\text { B. parapertussis } \\
\text { B. parapertussis } \\
\text { B. parapertussis } \\
\text { B. pertussis } \\
\text { B. pertussis } \\
\text { B. pertussis } \\
\text { B. pertussis } \\
\text { B. pertussis } \\
\text { B. pertussis } \\
\text { B. pertussis } \\
\text { B. pertussis } \\
\text { B. pertussis } \\
\text { B. pertussis } \\
\text { B. pertussis } \\
\text { B. pertussis } \\
\text { B. bronchiseptica } \\
\text { B. bronchiseptica } \\
\text { B. bronchiseptica } \\
\text { B. bronchiseptica }\end{array}$ &  \\
\hline
\end{tabular}

${ }^{a}$ Abbreviations: ATCC, American Type Culture Collection, 12301 Parklawn Drive, Rockville, Md.; Baumann, P. Baumann, Retina Foundation, Boston, Mass.; CCEB, Czechoslovak Collection of Entomogenous Bacteria, Na cvicisti 2, Prague 6; H, S.D. Henriksen, Kaptein W. Wilhelmsen og Frues Bakteriologiske Institutt, University of Oslo, Norway; IID, Institute of Infectious Diseases, University of Tokyo, Japan; Lacey, B. W. Lacey, Department of Bacteriology, Westminster Medical School, London; Lautrop, H. Lautrop, Statens Seruminstitut, Copenhagen; MJT, M. J. Thornley, Low Temperature Research Station, Cambridge; MSU, M. R. C. Microbial Systematics Unit, University of Leicester, England; NCIB, National Collection of Industrial Bacteria, Torry Research Station, Aberdeen; NCPPB, National Collection of Plant Pathogenic Bacteria, Ministry of Agriculture, Fisheries and Food, Plant Pathology Laboratory, Milton Road, Harpenden, Herts, England; NCTC, National Collection of Type Cultures, Central Public Health Laboratory, Colindale Avenue, London N.W.9., England; Owen, C. R. Owen, National Institute of Allergy and Infectious Diseases, Rocky Mountain Laboratory, Hamilton, Mont.; PHL, Leics, Public Health Laboratory, Leicester, England; Wey, Central Veterinary Laboratory, Weybridge, England.

$b_{\text {Holotype, type status }}(2,3,73)$.

$c$ Proposed working type, type status $(2,3,73)$.

$d$ Co-type, type status $(2,3,73)$.

e Neotype, type status $(2,3,73)$.

$f$ Paratype, type status $(2,3,73)$.

g Recent studies $(3,62)$ suggest it is not suitable as a type strain, but is probably Moraxella nonliquefaciens. 
horse and sheep blood was tested on BM agar layered over with BM agar containing $10 \%$ (wt/vol) horse or sheep blood. Requirement for increased $\mathrm{CO}_{2}$ concentration was determined by incubating in air with $5 \%$ $\mathrm{CO}_{2}$.

Resistance tests. Tests were carried out on BM agar. Growth on bile salts was tested on media containing 5 , 10 , or $40 \%(\mathrm{wt} / \mathrm{vol})$ bile salts (Oxoid); tolerance to sodium chloride was determined on agar containing 0 , $0.5,3.0,4.5,6.0,7.5$, or $9.0 \%$ (wt/vol) sodium chloride. BM without sodium chloride was prepared from single constituents omitting $\mathrm{NaCl}$; it contained only a small amount of sodium chloride (about $0.04 \%$ ) derived from the added serum.

Sensitivity to the pteridine compound $0 / 129(2,4$ diamino, 6-7 di-iso propyl pteridine) was determined by placing paper disks containing $40 \mu \mathrm{g}$ of $0 / 129$ onto streaked agar plates (the disks were soaked in a $0.4 \%$ ethanolic solution of $0 / 129$ and dried at $37 \mathrm{C})$. Dye sensitivity was tested by the paper strip method (19): paper strips were soaked in aqueous solutions of the following dyes: basic fuchsin (BDH) $(5 \mu \mathrm{g} / \mathrm{ml})$, methyl violet (E. Gurr Ltd.) $(2.5 \mu \mathrm{g} / \mathrm{ml})$, pyronin G (BDH) $(1.25 \mu \mathrm{g} / \mathrm{ml})$, safranin $0(\mathrm{BDH})(1.25 \mu \mathrm{g} / \mathrm{ml})$, and thionine (BDH) $(1.25 \mu \mathrm{g} / \mathrm{ml})$. Sensitivity to antibiotics was measured using disks placed on plates streaked from 48-h-old cultures. The disks contained the following quantities of antibiotics: penicillin $(5 \mathrm{U})$, streptomycin $(100 \mu \mathrm{g})$, chloramphenicol $(200 \mu \mathrm{g})$, aureomy cin $(250 \mu \mathrm{g})$, terramycin $(250 \mu \mathrm{g})$, ery thromycin $(10 \mu \mathrm{g})$, tetracycline $(250 \mu \mathrm{g})$, sulfonamide (1 $\mathrm{mg})$, neomycin $(250 \mu \mathrm{g})$, novobiocin $(50 \mu \mathrm{g})$, oleandomy cin $(100 \mu \mathrm{g})$, nitrofurantoin $(200 \mu \mathrm{g})$, and bacitracin $(25 \mathrm{U})$. Bactrim Roche disks (Oxoid) containing $25 \mu \mathrm{g}$ of trimethoprim-sulfamethoxazole and optochin disks (Oxoid) containing $25 \mu \mathrm{g}$ of ethylhydrocupreine were tested similarly. Sensitivity to $M$ and $B 938$ (4:4'-diamidinodiphenylamine dihydrochloride, May and Baker Co.) was determined by streaking cultures onto BM agar containing 12.5 $\mathrm{mg} /$ liter. Growth in the presence of potassium tellurite, sodium azide, thallous acetate, and sodium nitrite was tested on BM agar containing $320 \mathrm{mg} / \mathrm{liter}$, $75 \mathrm{mg} /$ liter, $500 \mathrm{mg} /$ liter, and $5 \mathrm{~g} /$ liter, respectively. Growth in the presence of phenol was determined on BM agar containing $0.1,0.2,0.3,0.4$, or $0.5 \%$ (wt $/ \mathrm{vol}$ ) phenol.

The ability to grow at $5,10,15,25,30,35,37$, and $44 \mathrm{C}$ was determined on BM agar incubated for 10 days. Heat resistance was measured by adding $0.5 \mathrm{ml}$ of bacterial suspension (a BM slant grown for $48 \mathrm{~h}$ washed off in $5 \mathrm{ml}$ nutrient broth) to $4.5 \mathrm{ml}$ of nutrient broth at $56 \mathrm{C}$. After intervals of 5, 10, 15 and $30 \mathrm{~min}$, loopfuls were plated onto BM agar and incubated for 5 days.

Biochemical tests. Catalase activity was detected by the addition of " 20 volume" hydrogen peroxide to 48-h-old BM agar cultures. Peroxidase activity was determined by the addition of reagent $(0.5$ crystalline benzidine hydrochloride dissolved in $3 \mathrm{ml}$ of glacial acetic acid to which an equal volume of " 20 volume" hydrogen peroxide had been added) to a BM agar culture and observing the development of a blue color. Oxidase was tested by the method of Kovács (44). BM agar slopes containing $0.25 \%(\mathrm{wt} / \mathrm{vol})$ cysteine hydrochloride were used for the detection of hydrogen sulfide; lead acetate paper strips suspended above the medium were used as indicator. Phosphatase was determined on BM agar containing $100 \mathrm{mg}$ of phenolphthalein diphosphate per liter (added as $10 \mathrm{ml}$ of a sterile $1 \%$ [wt/vol] aqueous solution to the autoclaved BM agar). After incubation for 5 days, the plates were inverted over strong ammonia solution and examined for a red color around the colonies. Gelatinase activity was determined on BM agar containing $0.4 \%$ (wt/vol) gelatin by flooding the plates, after 7 days incubation, with acid mercuric chloride solution. Hydrolysis of starch was determined on BM agar containing 0.5 soluble starch. After incubation for 7 days, some of the bacterial growth was scraped aside and the plates were flooded with Lugol iodine. Turbidity from egg yolk was determined on BM agar containing $10 \%$ (vol/vol) concentrated egg yolk emulsion (Oxoid) and an additional $1 \%$ (wt/vol) sodium chloride. Casein hydrolysis was recorded as clear zones on BM agar containing $20 \%$ (vol/vol) sterile skim milk. Esculin hydrolysis was determined on BM agar containing $0.05 \%$ ferric ammonium citrate and $0.5 \%$ esculin; after incubation the plates were examined for a brown coloration. Dextran or levan production was tested on BM agar plates containing $5 \%$ sucrose, which were incubated at optimum temperature; large mucoid colonies were taken to indicate dextran or levan production. Tetrazolium reduction was tested on $\mathrm{BM}$ agar plates adjusted to $\mathrm{pH}$ 6.0 and containing $1 \%$ (wt/vol) glucose and 2:3:5triphenyl tetrazolium chloride $(75 \mathrm{mg} /$ liter $)$ and examined after incubation for red-insoluble formazan. Production of ammonia was tested on BM agar plates containing $10 \mathrm{~g}$ of peptone/liter (L37, Oxoid) in place of nutrient broth no. 2 and casein hydrolysate. They were tested with Nessler reagent after incubation. Urease activity was tested by the micromethod of Lautrop (49). Arginine hydrolysis was detected using Thornley medium (80) modified as a micromethod. The medium was dispensed in $0.6-\mathrm{ml}$ volumes in tubes $(10$ by $1.2 \mathrm{~cm})$ and heavily inoculated. Development of a pink color was recorded after 2 and $24 \mathrm{~h}$. Nitrate reduction was determined on $\mathrm{BM}$ agar plates containing $0.1 \%$ (wt/vol) $\mathrm{KNO}_{3}$ and tested for nitrite by adding Griess-Ilosvay reagents. Deoxyribonuclease (DNase) activity was determined on the following medium: DNase agar (Oxoid) (39 g), Dowex 1-X8 (5 $\mathrm{g})$, distilled water $(940 \mathrm{ml})$; mixture A was added after autoclaving. After incubation, plates were flooded with $1 \mathrm{M} \mathrm{HCl}$ and examined for clear zones. Production of hydrogen cyanide was determined on BM blood agar by use of sodium picrate indicator papers (68). Methyl red and Voges-Proskauer tests were determined in the following medium: brain-heart infusion (Oxoid) (37 g), glucose (5 g), $\mathrm{K}_{2} \mathrm{HPO}_{4}(5 \mathrm{~g})$, distilled water $(940 \mathrm{ml})$. After sterilization by autoclaving, mixture $\mathrm{A}$ was added, and the medium was dispensed in $30-\mathrm{ml}$ bottles. After incubation, cultures were tested with methyl red indicator and O'Meara reagent.

Hydrolyses of xanthine and of tyrosine were determined by the method of Gordon and Smith (30) 
using BM agar containing $0.5 \%$ (wt/vol) tyrosine or $0.4 \%$ (wt/vol) xanthine. Pigment production from tyrosine was also recorded. Phenylalanine deaminase activity was determined on BM agar containing $2 \mathrm{~g}$ of DL- $\beta$-phenylalanine per liter instead of the nutrient broth no. 2. Aqueous ferric chloride solution (10\%, wt/vol) was used as the test reagent. Hydrolysis of Tweens $20,40,60$, and 80 was determined on BM agar containing $1 \%(\mathrm{vol} / \mathrm{vol})$ Tween. Precipitation around colonies was recorded as positive. Some strains produced a clear zone around growth on Tween 80 , and this was also recorded. Production of acid from carbohydrates was determined on BM agar containing $0.2 \%(\mathrm{wt} / \mathrm{vol})$ tryptone in place of nutrient broth no. 2 , and only $0.1 \%(\mathrm{wt} / \mathrm{vol}$ ) casein hyrolysate. The carbohydrates were prepared as $10 \%$ aqueous solutions and sterilized by filtration. After the basal medium was autoclaved, the carbohydrates were added to give a final concentration of $1 \%$. Plates were incubated for 7 days, and acid production was detected by adding 2 drops of sterile $0.04 \%$ (wt/vol) aqueous bromothymol blue adjusted to $\mathrm{pH} 7.2$. This technique was used to avoid inhibition of strains of Bordetella pertussis and some other strains by indicator incorporated in the medium. The following carbohydrates were tested: glucose, lactose, xylose, salicin, raffinose, $\alpha$-methyl-Dglucoside, ribose, rhamnose, mannose, inositol, cellobiose, fructose, inulin, dextrin, dulcitol, L(+)arabinose, adonitol, sorbitol, galactose, maltose, sucrose, mannitol, glycerol, and glucosamine hydrochloride. Glucose and lactose were also tested at $10 \%$ concentration. The mode of glucose metabolism (i.e. oxidative or fermentative) was determined by inoculating $1 \%$ glucose plates in duplicate and incubating one set aerobically and the other anaerobically in an anaerobic jar.

Computer methods. A numerical taxonomy program written at the Microbial Systematics Unit, Univ. of Leicester, England, was used. The majority of characters were two state and were coded 1 for positive, 0 for negative. Sixteen tests were scored as multistate characters, scoring 0 for negative and 1,2 , or 3 for increasing grades of positive response. Five of the 139 characters recorded were deleted from the data matrix because all strains gave identical results. Growth on $0.5 \%$ sodium chloride agar, growth at $30 \mathrm{C}$, and growth in the presence of optochin were positive for all strains, and no strain was capable of producing hydrogen cyanide or of fermenting dulcitol. The final $n \times t$ matrix contained 134 characters and 194 OTUs (strains). The limitations of the computer prevented all 194 OTUs from being sorted in a single run; this was overcome by selecting 89 OTUs with the specific epithets pertussis, parapertussis, and bronchiseptica and sorting these first (computation 1). Chosen representatives of the clusters that were found were then included with the remaining OTUs in the second run (computation 2). The similarity $(s)$ coefficient employed, $S_{G}$, was that of Gower (32) using both positive and negative similarities. Some trials were made with the coefficient $S_{J}$, which excludes negative matches; the results were very similar and revealed no additional points of interest. Both single linkage and unweighted average linkage (UPGMA) clustering (75) were used and gave very similar phenograms; results of the average linkage method are reported here. Vigor and pattern statistics (69) were also calculated.

\section{RESULTS}

Clustering of the strains. The results of two computations are presented as phenograms (Fig. 1 and 2). Figure 1 (computation 1) illustrates that all but three strains of Bordetella fell into three very tight clusters. Cluster 1 contained 30 strains received as Bordetella pertussis; cluster 2 contained 21 strains received as Bordetella parapertussis; cluster 3 contained 35 strains received as Bordetella bronchiseptica. Strain J70 (Bordetella bronchiseptica ATCC 15101) fell just outside cluster 3 but still retained an average similarity of over $91 \%$ with the rest of the cluster. Two aberrant strains, J44 and J67, are discussed later.

Figure 2 is a simplified phenogram showing the arrangements of all the strains in computation 2. These can be seen to form 13 clusters which are separated at the $66 \%$ similarity level into two large groups, A and B. Group A contains organisms of the genera Haemophilus, Actinobacillus, and Pasteurella that are discussed in a companion paper (72). Group B contains 150 strains, of which 134 fell into nine fairly well-separated clusters. The remaining 16 strains were satellites of one or another of these clusters.

Baumann, Doudoroff, and Stanier (8) have pointed out that, in the oxidase-negative moraxellas, glucose is metabolized by a nonspecific aldose dehydrogenase enzyme which can also oxidise D-galactose, D-mannose, D-ribose, D-xylose, L-arabinose, L-rhamnose, maltose, lactose, and cellobiose. Thus, production of acid from these sugars is highly correlated with the ability to produce acid from glucose. None of our strains was able to produce acid from other carbohydrates if it could not produce acid from glucose. Therefore carbohydrate acidification tests are not truly independent characters, and consequently their inclusion tends to increase the similarities between strains that attack no carbohydrates by increasing the number of negative matches.

For these reasons computation 2 was repeated after deleting 22 carbohydrate characters, retaining only the production of acid from $1 \%$ and $10 \%$ glucose and lactose, acid from $1 \%$ glucose anaerobically, and alkali from $1 \%$ lactose (computation 3). The simplified phenogram is shown in Fig. 3. There are relatively few differences from Fig. 2. The co-phenetic correlation coefficient for computation 3 was 0.81 (the correlation between the original 


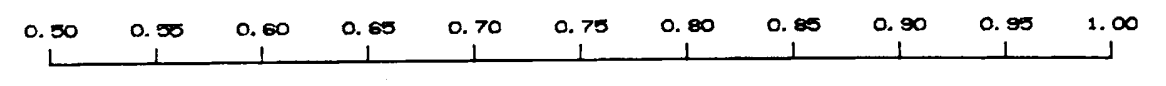

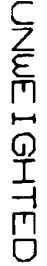

$D$
劣
D
尚

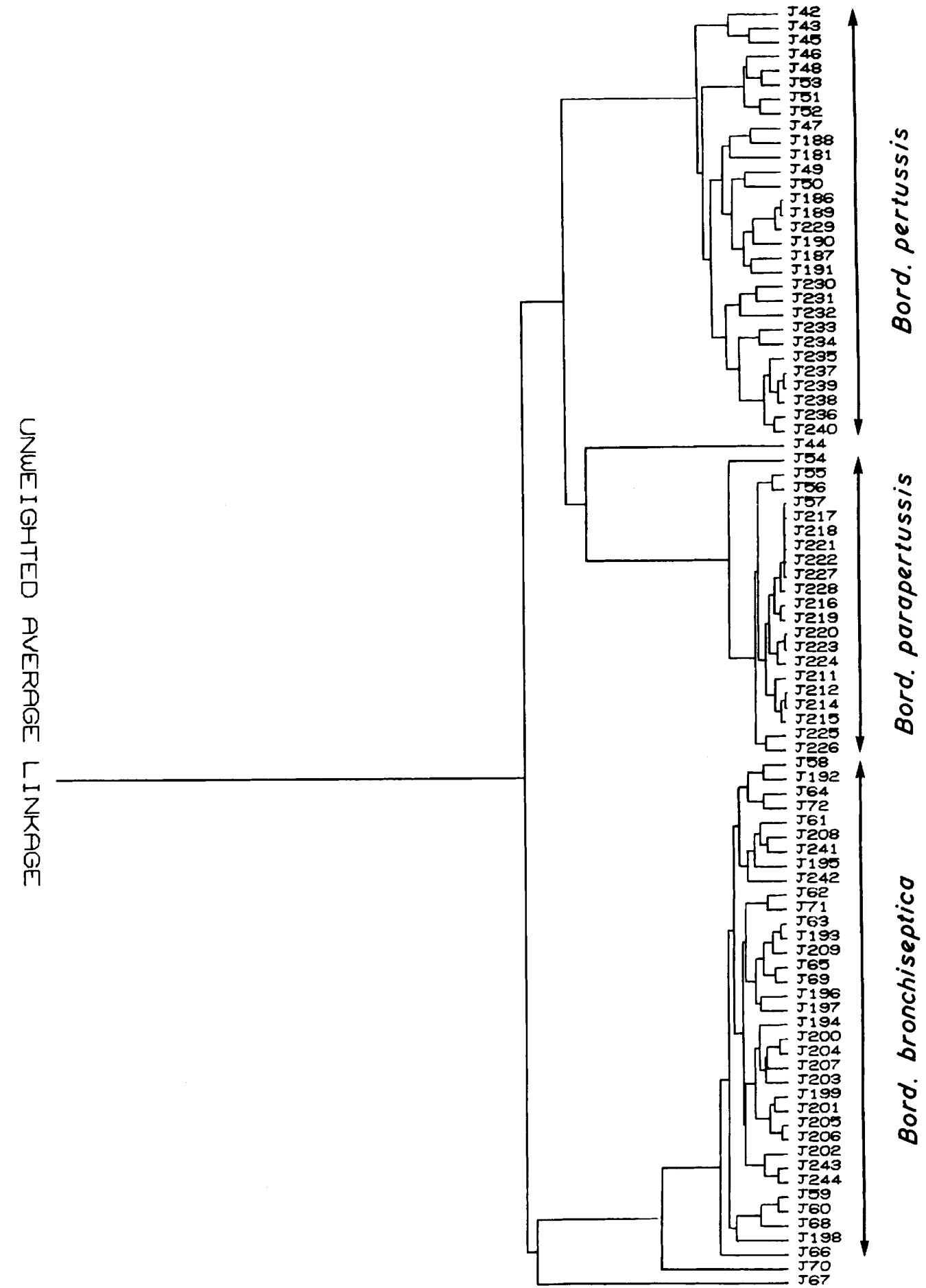

FIG. 1. Phenogram of strains of Bordetella, based on all 134 characters, Gower's Coefficient including negative matches, and UPGMA clustering. The co-phenetic correlation is 0.96 . The similarity scale is directly comparable with that of Fig. 2, and is comparable with that of Fig. 3 if adjusted so that the new similarities are $(134 S-22) / 112$. 


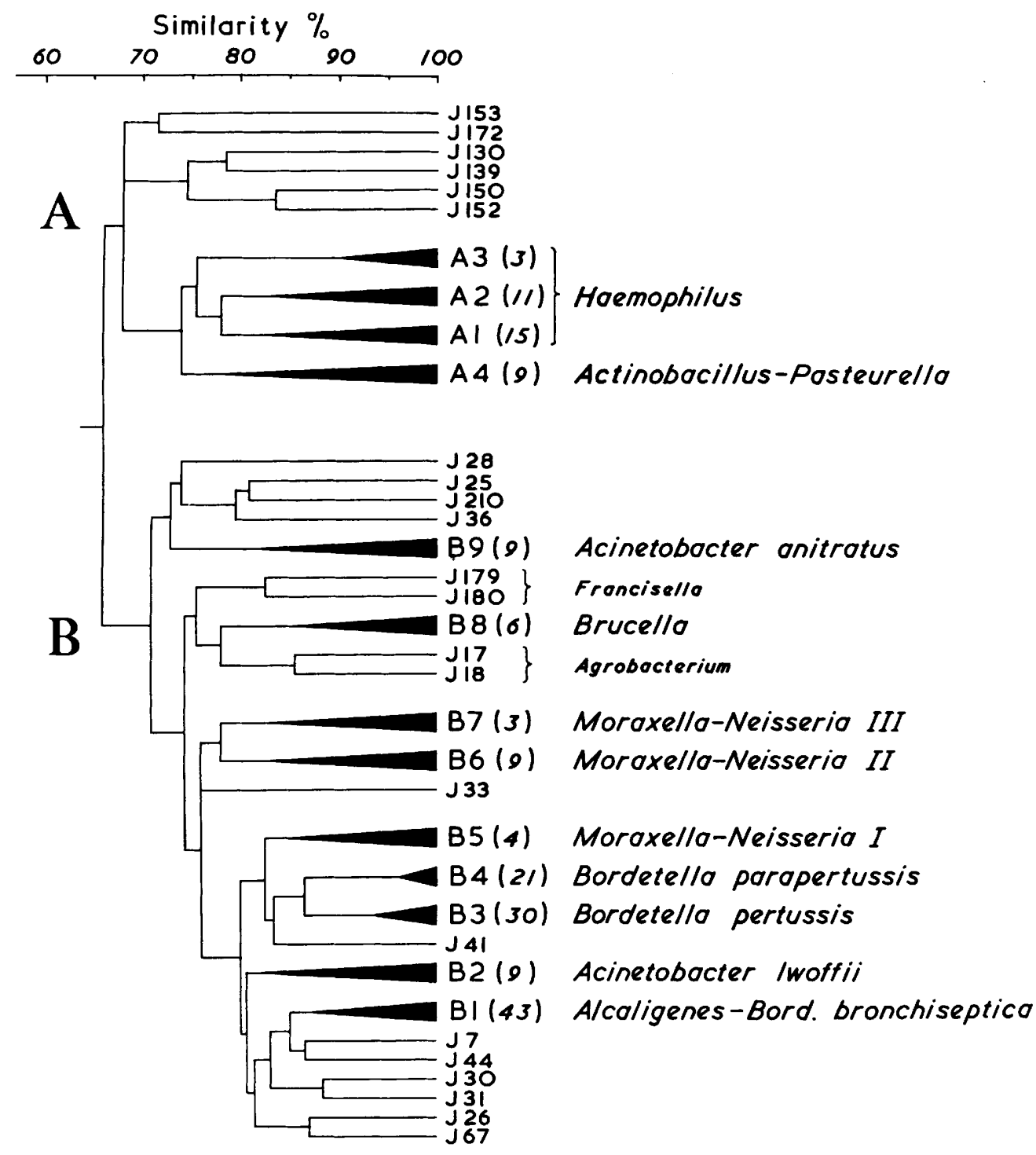

FIG. 2. Simplified phenogram of all strains based on all 134 characters, Gower's Coefficient including negative matches, and UPGMA clustering, redrawn to outline the major clusters. The co-phenetic correlation is 0.85 . The apex of a triangle indicates the lowest similarity at which any branch arises among the strains in that cluster.

similarity values and those in the phenogram, ideally 1.0), showing that the phenogram is quite a satisfactory representation of the similarity matrix from which it was derived. In addition, the mean square distance from the line of perfect agreement in co-phenetic scatter diagrams (75) was calculated for each OTU. Those OTUs that showed highest values (and thus were OTUs whose relationships were most distorted by clustering) were J26, J128, and $\mathrm{J} 172$. Most of the other OTUs with rather high values were members of the Moraxella-Neisseria clusters. High values would be expected from OTUs that were aberrant or intermediate between clusters; our general. experience is that this is commonly so, although the trend is not very well shown here.

For several reasons we believe that Fig. 3 is a more accurate reflection of the taxonomy of these organisms than Fig. 2. A three-dimensional model based on average intergroup distances (using $1-S_{G}$ as a measure of distance) was in better agreement with Fig. 3 than Fig. 2 (R. Johnson, Ph.D. thesis, Univ. of England, 


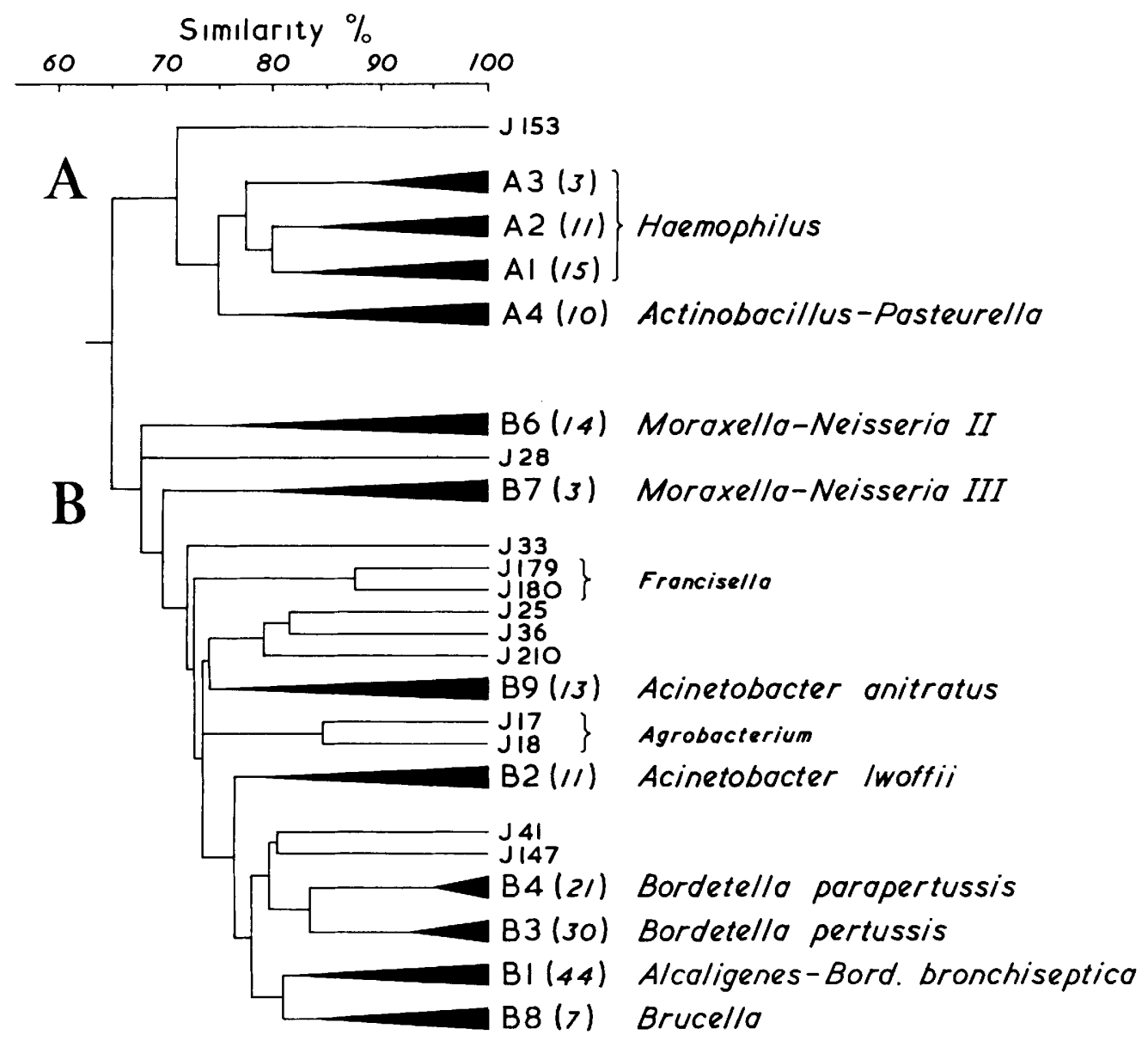

FIG. 3. Simplified phenogram of all strains from computation omitting 22 carbohydrate characters (computation 3). Conventions as in Fig. 2. The co-phenetic correlation is 0.81 .

Leicester, 1972). In Fig. 3, three aberrant strains of Neisseria and Moraxella mentioned later (J150, J152, and J139), and also Moraxella bovis $\mathrm{J} 130$, appeared in group $\mathrm{B}$ together with other strains of these genera rather than in group A (as in Fig. 2). Also, the arrangment of clusters in Fig. 3 is in better accord with current views $(50)$. We therefore base our conclusions principally on the results illustrated in Fig. 3, and the composition of the main clusters in that figure is given in Table 2.

Cluster Bl contained 44 strains of Bordetella bronchiseptica and Alcaligenes (mainly $A$. faecalis). Within B1 the strains of $B$. bronchiseptica formed a tight $95 \%$ phenon except for $\mathrm{J} 70$, which joined at $90 \% \mathrm{~S}$. The strains of Alcaligenes did not form a similar tight cluster but were attached in ones, twos, or threes to the main stem in the range 85 to $89 \% S$. Strain $\mathrm{J} 1$ ( $A$. denitrificans), however, joined the bronchiseptica phenon at $93 \%$ S.

Cluster B2 contained strains identified by us as Acinetobacter lwoffii. Although a type strain for this species is not available, the identification of these strains as $A$. lwoffii rests on the agreement with the original description (5), with results of other workers $(8,59,60,81)$, and with the inclusion in B2 of two strains, J27 and $\mathrm{J} 29$, believed to be authentic $(8,73)$.

Strains of this cluster were received under the names Acinetobacter lwoffi, Moraxella lwoffii, Alcaligenes viscosus, and Alcaligenes metalcaligenes, and just included in this cluster were strains received as Mima polymorpha var. oxydans and Moraxella osloensis.

Clusters B3 and B4 correspond to Bordetella 
TABLE 2. Strains of the group B clusters

\begin{tabular}{|c|c|c|c|}
\hline Cluster & $\begin{array}{l}\text { No. in } \\
\text { cluster }\end{array}$ & Strain no. & Designation of cluster \\
\hline B1 & 44 & $\begin{array}{l}\mathrm{J} 1-\mathrm{J} 8, \mathrm{~J} 58-\mathrm{J} 66, \mathrm{~J} 68-\mathrm{J} 72, \mathrm{~J} 192-\mathrm{J} 209 \\
\mathrm{~J} 241-\mathrm{J} 244 .\end{array}$ & $\begin{array}{l}\text { Alcaligenes faecalis and } \\
\text { Bordetella bronchiseptica }\end{array}$ \\
\hline B2 & 11 & $\begin{array}{l}\mathrm{J} 9-\mathrm{J} 13, \mathrm{~J} 27, \mathrm{~J} 29, \mathrm{~J} 132-\mathrm{J} 133 \\
\mathrm{~J} 136^{a}, \mathrm{~J} 140^{a} .\end{array}$ & Acinetobacter lwoffii \\
\hline B3 & 30 & $\begin{array}{l}\text { J42-J43, J45-J53, J181, J186-J 191, } \\
\text { J229-J240. }\end{array}$ & Bordetella pertussis \\
\hline B4 & 21 & J54-J57, J211-J212, J214-J228. & Bordetella parapertussis \\
\hline B6 & 14 & $\begin{array}{c}\mathrm{J} 128-\mathrm{J} 131, \mathrm{~J} 134, \mathrm{~J} 137, \mathrm{~J} 139, \mathrm{~J} 143- \\
\mathrm{J} 144, \mathrm{~J} 146^{\alpha}, \mathrm{J} 148-\mathrm{J} 150, \mathrm{~J} 152\end{array}$ & Moraxella and Neisseria II \\
\hline B7 & 3 & $\mathrm{~J} 141-\mathrm{J} 142, \mathrm{~J} 145$. & Moraxella and Neisseria III \\
\hline B8 & 7 & $\begin{array}{l}\text { J44, J154, J 158-J 159, J161-J162, } \\
\text { J165. }\end{array}$ & Brucella \\
\hline B9 & 13 & $\begin{array}{l}\mathrm{J} 23-\mathrm{J} 24, \mathrm{~J} 26, \mathrm{~J} 30-\mathrm{J} 32, \mathrm{~J} 34-\mathrm{J} 35 \\
\mathrm{~J} 37-\mathrm{J} 40, \mathrm{~J} 67 .\end{array}$ & Acinetobacter anitratus \\
\hline Unclustered & 7 & $\begin{array}{l}\mathrm{J} 25, \mathrm{~J} 28, \mathrm{~J} 33, \mathrm{~J} 36, \mathrm{~J} 41, \mathrm{~J} 147^{a}, \\
\mathrm{~J} 210\end{array}$ & \\
\hline
\end{tabular}

${ }^{a}$ Cluster 5 (Moraxella-Neisseria I) was formed only in computation 2, and its four members, indicated by the footnote $a$, were redistributed in computation 3 .

pertussis and Bordetella parapertussis, respectively. Within B3 there was no definite structure corresponding to antigenic phases, so that the phenetic changes associated with roughness were evidently slight.

Cluster B5 of Fig. 2 does not appear in Fig. 3 , as its strains have been redistributed; strains $\mathrm{J} 136$ and J140 have moved into cluster B2, strain J146 has joined cluster 6 , whereas J147 is now a satellite of B3 and B4.

Clusters B6 and B7 contained strains of several species of Moraxella and Neisseria but there was no differentiation of the two, which is not unexpected: these genera are close taxonomically, and the speciation within them is uncertain.

Cluster B8 contained four nomenspecies of Brucella, the three classical ones, $B$ abortus, $B$. suis, and $B$. melitensis, and also the organism from the $\operatorname{dog}, B$. canis. They formed an $83 \%$ phenon; there were too few strains to show whether the internal arrangement corresponds with the nomenspecies. Though fewer characters were available for these strains, we believe this deficiency has not greatly biased the relationships involving Brucella.

Cluster B9 represented Acinetobacter anitratus. It also included strains received as
Achromobacter haemolysans (J26), Achromobacter haemolyticus (J31, J32), A chromobacter conjunctivae (J34), Achromobacter mucosus (J35), and Achromobacter lacticus (J37). The grouping of the last two agrees with previous work $(8,81)$, but there are some discrepancies regarding the first four strains (see Discussion).

Strains falling outside the clusters. Several unclustered strains require comment. J25 (Acinetobacter calcoaceticus) most closely resembled strains of cluster B9 at around $75 \%$ similarity. It differed from cluster B9 in being sensitive to $5 \%$ bile salts, in its dye sensitivities, and in being resistant to penicillin. It raises problems of nomenclature (see Discussion). Achromobacter liquefaciens ATCC 15716 (J36) did not share high similarities with any cluster. Thornley (81) examined this strain and found most of the cells to be gram positive. We confirmed this although several of the results obtained (particularly production of hydrogen sulfide, acid from various carbohydrates, and ammonia from peptone) differed from those obtained by Thornley. It probably does not belong to this area of bacteria. The results obtained for J41 (also called Vibrio 0 1) agreed largely with those obtained by Fewson (26, 27). This strain shared high similarities with 
cluster B3 but differed from these strains in being oxidase negative, lecithinase positive, tyrosinase positive, producing hydrogen sulfide, growing on nutrient agar, and in clearing Tween 80. Furthermore, it was resistant to penicillin but sensitive to sulfonamide.

Strain J44 (NCTC 8631) was received as Bordetella pertussis and at first seemed to be an aberrant strain of Bordetella (Fig. 1 and 2). In computation 3 it fell into B8 (Brucella). When tested by slide agglutination it gave a strong agglutination in Brucella antiserum but did not agglutinate in Bordetella pertussis antiserum. Bacon et al. (6) obtained a value of $57.5 \%$ for the $\mathrm{G} / \mathrm{C}$ ratio of this strain, which is typical of other reported values for Brucella. AIso, examination of crude protein extracts by polyacrylamide gel electrophoresis showed that J44 had a very similar protein pattern to J159 (a strain of Brucella melitensis). Other characters which it shared with strains of the Brucella cluster, but in which it differed from the strains of $B$. pertussis, included its resistance to 0/129 and Bactrim Roche and its production of urease. There seems little doubt that J44 belongs to Brucella, although it is somewhat atypical, and the National Collection of Type Cultures now lists it as Brucella melitensis.

We suspect that J139 became contaminated during study, as it was not saccharolytic on retesting. The ability of strain J130 to attack carbohydrates was, however, confirmed on checking. Its correct designation is still uncertain; it is clearly not a strain of Moraxella bovis.

A single strain of Noguchia granulosis (J153) was studied. It was an isolated member of group A. It was a gram-negative rod with a tendency to pleomorphism and grew on simple media but was inhibited by bile salts. Acid was not produced from lactose. It was nonmotile and catalase positive, and reduced nitrate. The oxidase reaction was weakly positive. It differed from the published descriptions of Noguchia granulosis $(55,56,82)$ in not fermenting lactose, in motility, and in having a dull, nonviscid matte colony, and in growing well on nutrient agar and anaerobically. This raises doubts as to its authenticity. Finally, J172 (Pasteurella haemolytica T) has (Fig. 3) taken up a position with the other pasteurellas in group A.

Characters of the groups and clusters. Characters shown by all strains have been listed under Materials and Methods. All except three strains in group A could grow anaerobically and were fermentative, as they produced acid from glucose anaerobically. The three excep- tions were $\mathrm{J} 150$ and $\mathrm{J} 152$ (Neisseria pharyngis) and $\mathrm{J} 139$ (Moraxella bovis). Only one (J180, Francisella novicida) of the 150 strains in group B was able to grow under strictly anaerobic conditions. However, some strains were able to grow anaerobically in the presence of nitrate, presumably because nitrate could act as an alternative electron acceptor to oxygen. Some strains of group B could produce acid from glucose aerobically but not anaerobically, so that group B strains are predominantly aerobic and either oxidative or nonsaccharolytic. Strains of group B also showed the following characteristics with few exceptions: they were gram negative, not markedly pleomorphic, nonpigmented (except cluster B4) did not require $\mathrm{CO}_{2}$, haematin, or NAD for growth, were catalase and peroxidase positive, esculin, DNase, methyl red, and Voges-Proskauer negative, and produced ammonia from peptone. Characters most useful for differentiating the clusters of group B are shown in Table 3. In Table 4 are shown the percentages of positive results in the clusters from which the hypothetical median organisms or the cluster centroids can be obtained $(51,70)$.

In Table 4 the strains of Alcaligenes and Bordetella bronchiseptica have been tabulated separately.

Reproducibility of results. The effects of poor test reproducibility on taxonomic work have been discussed by Sneath and Johnson (71), who presented detailed findings from the present study. This was investigated by testing 21 strains in duplicate: the probability $(P)$ of an erroneous result averaged $1.713 \%$; if tests which gave identical results on both occasions in all 21 strains were excluded, the average value of $P$ was $2.24 \%$. These figures compare favorably with values of $4 \%$ or more found in other studies $(31,48,51,79)$. In effect it means that comparison of a strain against itself would result in a similarity of about 0.96 instead of the theoretical 1.0, which is satisfactory. The least reproducible tests were peroxidase, various morphological characters, and antibiotic sensitivities, hydrogen sulfide production, growth on bile salts, production of ammonia from peptone, and nitrate reduction.

Vigor and pattern statistics. The percentage difference between strains, i.e., the complement of similarity, can be partitioned into vigor and pattern difference, $D_{V}$ and $D_{P}$ (69). Vigor difference expresses the difference between strains in total metabolic activity as measured by the number of positive reactions. Pattern difference reflects which particular tests give positive results, and it attempts to make 


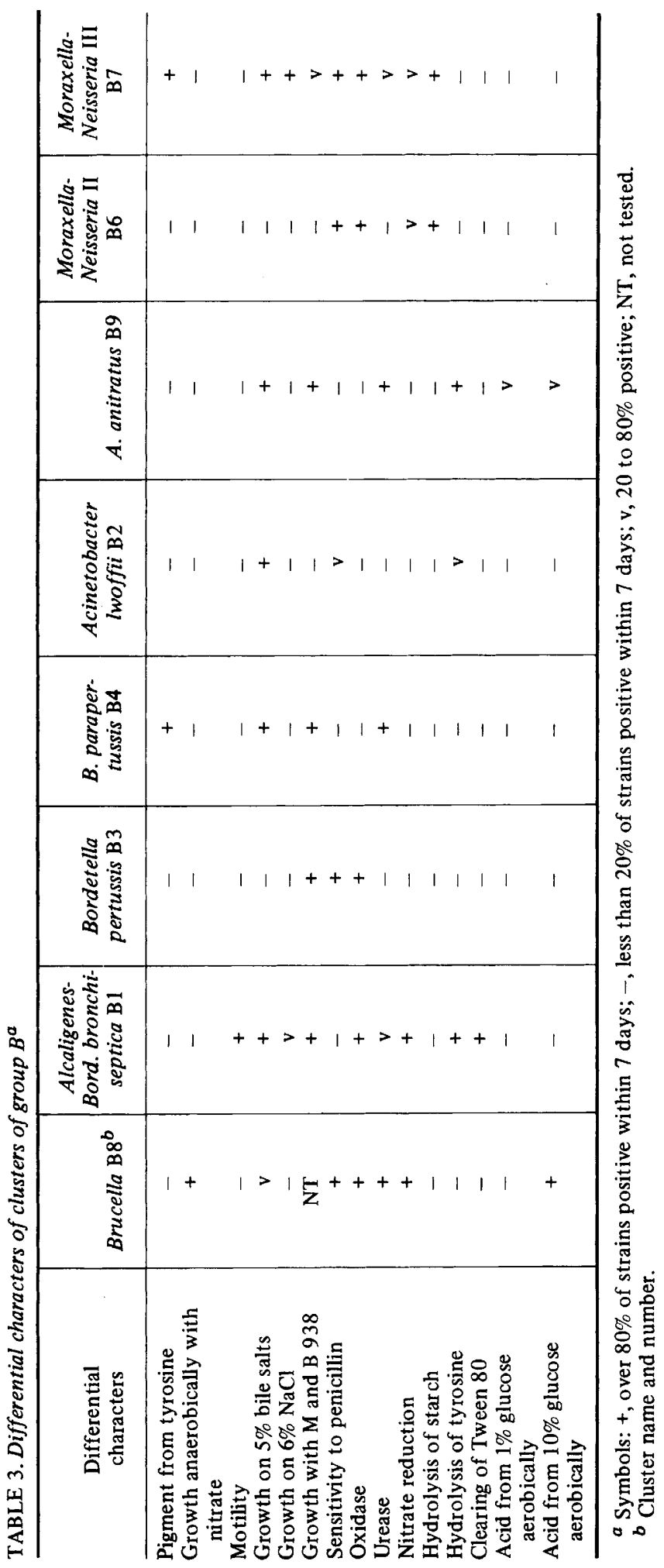




\begin{tabular}{|c|c|c|c|c|c|c|c|c|}
\hline 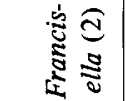 & o in & ○ & o: in & $00800 \frac{\mathrm{z}}{\mathrm{g}}$ & in요 & $00088^{\circ}$ & $\stackrel{5}{\mathbf{z}}$ & 08008800000 \\
\hline 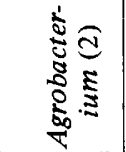 & 00 & 0 & ino & gogo: & 00 & $00088^{\circ}$ & 0 & ing80용ㅇㅇ \\
\hline  & 00 & $\bar{m}$ & $\bar{m} \Omega$ & 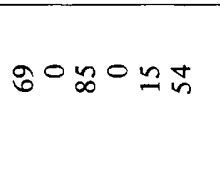 & 00 & $00088^{\circ}$ & $\cong$ &  \\
\hline  & 00 & 0 & $\circ$ & $00 \% \pm 0 \frac{5}{z}$ & $\circ \infty$ & 000880 & $\vec{z}$ & 动艺昌下0000\% \\
\hline 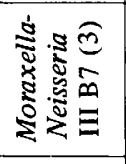 & 08 & $m$ & 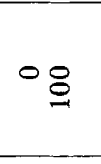 & 005080 & 00 & $000 \mathrm{mg}$ & 0 & $\circ 85088888 m 8$ \\
\hline 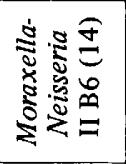 & og & \pm & $\vec{\sim} \approx$ & : さே゚ささ0 & $-\mathfrak{g}$ & $000 \% \infty \stackrel{\sim}{-1}$ & $\stackrel{\curvearrowright}{\sim}$ & 0000 సిষ \\
\hline  & 00 & 0 & 00 & $00880^{\circ}$ & 00 & 000880 & $\tilde{a}$ & 08808890000 \\
\hline 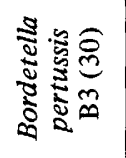 & 00 & $n$ & -ล̃ & mo0000 & 00 & $000-\pi n$ & $m$ & $00008-00000$ \\
\hline 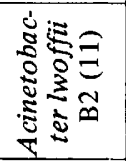 & 100 & $\stackrel{\infty}{-1}$ & $\circ 8$ & \% poroo & 00 & $00088^{\circ}$ & $a$ & 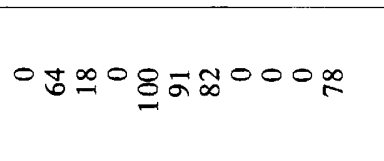 \\
\hline  & 00 & 0 & ố & 008000 & 00 & 000880 & $m$ & 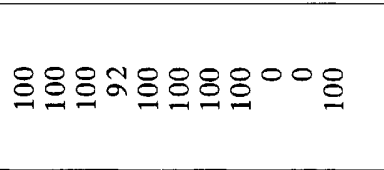 \\
\hline  & 00 & 0 & $0=$ & $0080 \pm 0$ & 00 & $00088^{\circ}$ & 0 & 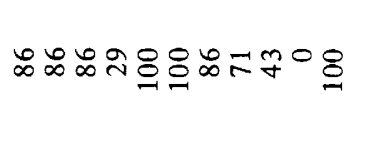 \\
\hline  &  & 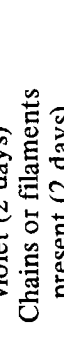 &  &  & 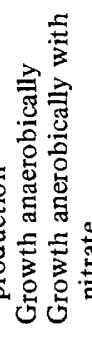 & 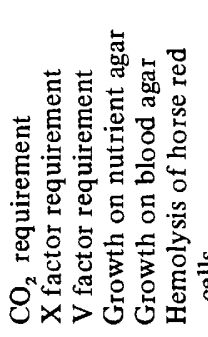 &  & 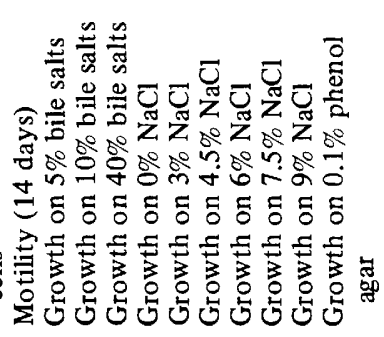 \\
\hline
\end{tabular}




\begin{tabular}{|c|c|c|c|c|c|c|c|c|c|c|c|c|c|}
\hline 4 & $\circ$ & $\circ$ & $\circ$ & $\vec{z} \quad \hat{z}$ & $\dot{z}$ & $\bar{z} \quad \hbar$ & 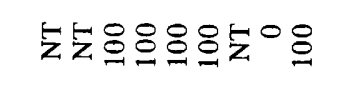 & $\underset{-1}{8}$ & 88. & 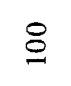 & $\circ$ & $\S \cong$ & 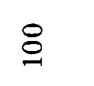 \\
\hline 0 & $\circ$ & $\circ$ & $\circ c$ & $\circ \AA$ & 0 & is 8 & 0 요요요요 & 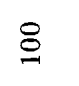 & @® & 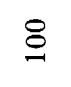 & 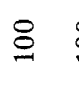 & 88 & 8 \\
\hline$f$ & $\circ$ & 0 & $\circ c$ & $\circ \stackrel{8}{\circ}$ & $\because$ & $\approx \&$ & 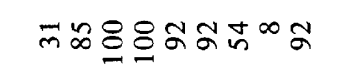 & 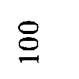 & 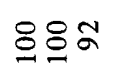 & 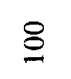 & 8 & ஓू & $\tilde{\alpha}$ \\
\hline \pm & $\circ$ & $\circ$ & $\circ \frac{1}{2}$ & $\stackrel{z}{z}$ & $\hat{z}$ & $\bar{z} \bar{z}$ & 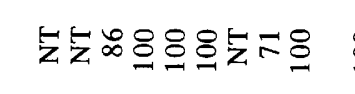 & 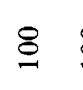 & 8.8 & \& & \pm & 8 & $i n$ \\
\hline 0 & 0 & 0 & 00 & 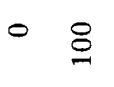 & $m$ & $m 5$ & 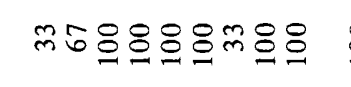 & $\cong$ & $8 \%$ & $\stackrel{8}{\circ}$ & 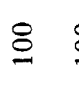 & $8:$ & 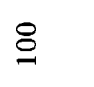 \\
\hline - & $r$ & - & $0 r$ & -2 & $\bar{\sim}$ & \pm 2 & 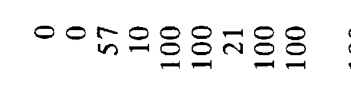 & 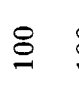 & $\cong \%$ & $\S$ & 2 & :̊ & 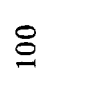 \\
\hline 0 & 0 & 0 & 00 & $\circ \cong$ & $\circ$ & 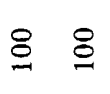 & $008 \% 8000 \%$ & 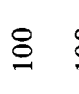 & 욤 & 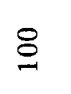 & 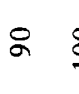 & 88 & 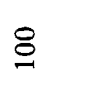 \\
\hline 0 & 0 & $\circ$ & $\circ 0$ & $\circ \stackrel{8}{ }$ & 0 & $\stackrel{8}{0}$ & $00 \mathrm{~m} g 8.0 \%$ & $@$ & ஜ:8 & $\cong$ & m & \&: & $\stackrel{8}{\circ}$ \\
\hline$\stackrel{\circ}{n}$ & $=$ & $\circ$ & $\circ 0$ & $\circ \quad$ & $\circ$ & $\circ \stackrel{8}{9}$ & 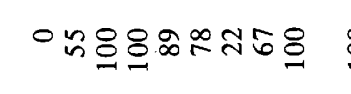 & 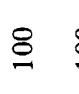 & $8 \infty 8$ & $\stackrel{-}{0}$ & $\infty$ & 8 & 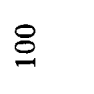 \\
\hline$\circ$ & 0 & 0 & 00 & $\circ \cong$ & $n$ & $\cong \cong$ & 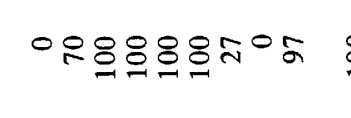 & 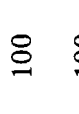 & ๕๕ă & $\stackrel{8}{8}$ & 8 & ¿̊ & $\approx$ \\
\hline 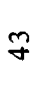 & 0 & 0 & $\circ £$ & $\nsubseteq \nsubseteq$ & $q$ & $\infty \nsubseteq$ & 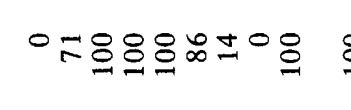 & $\nsubseteq$ & ৪:- & 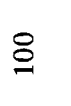 & $\infty$ & 8 & $\infty$ \\
\hline 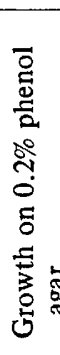 & 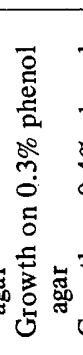 & 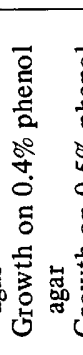 &  & 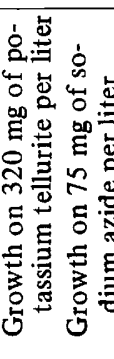 & 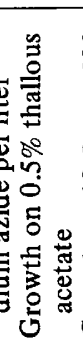 & 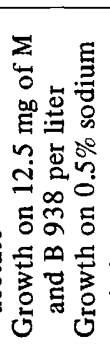 & 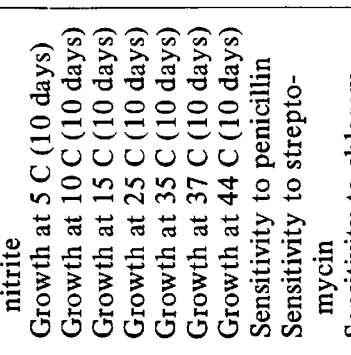 & 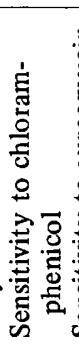 & 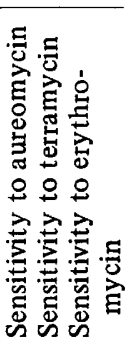 & 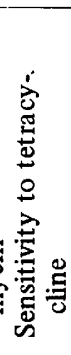 & 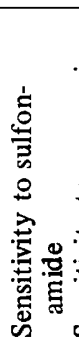 & 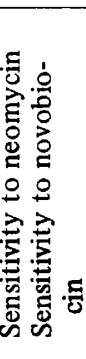 & 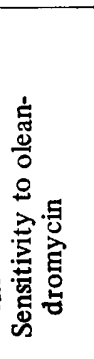 \\
\hline
\end{tabular}




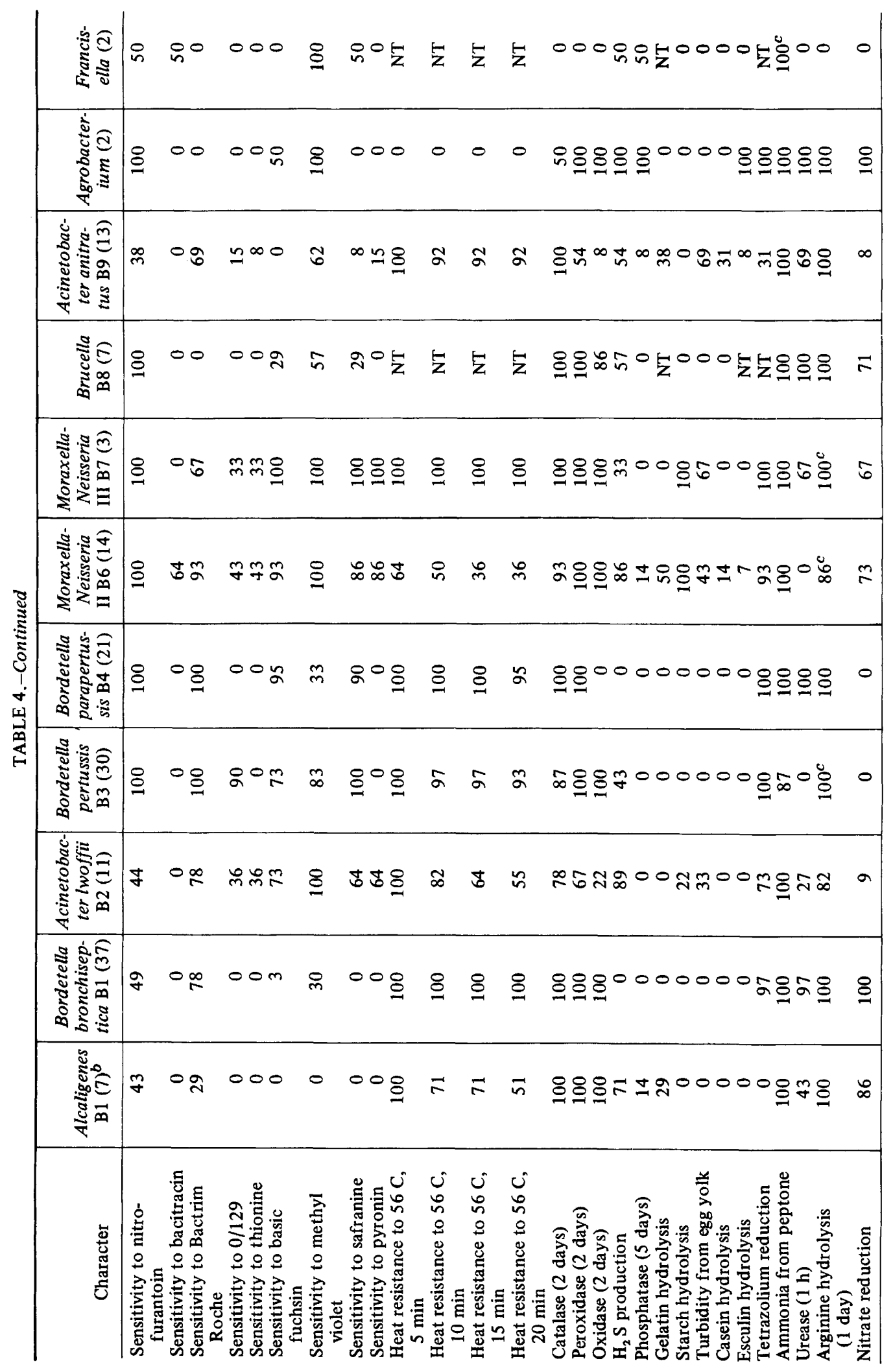




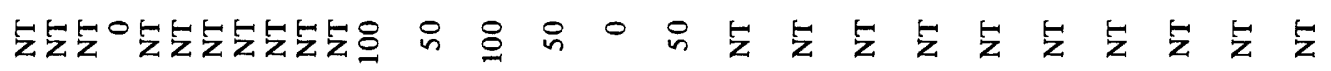

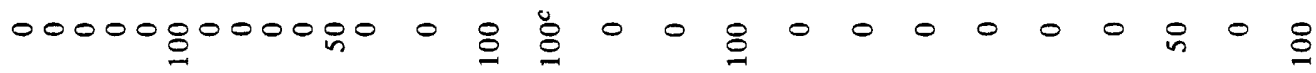

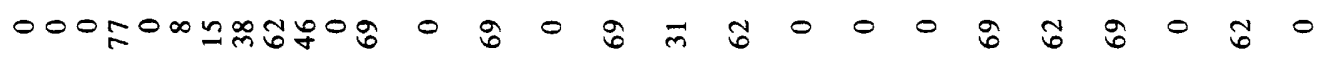

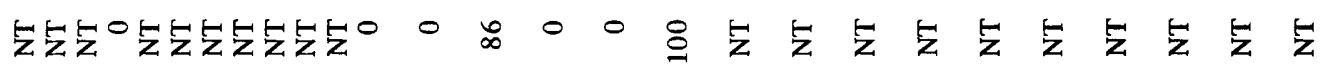
$000008858000000 \% 0000000000$

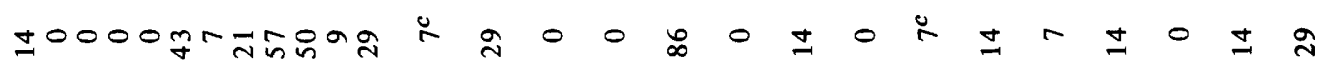

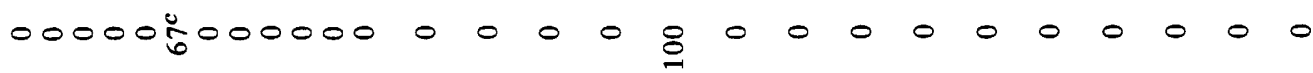
00000 in 00000000008000000000

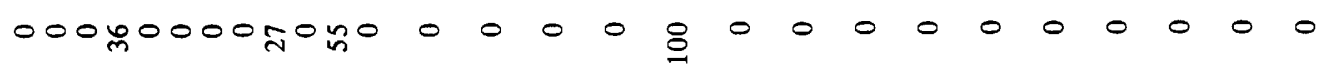

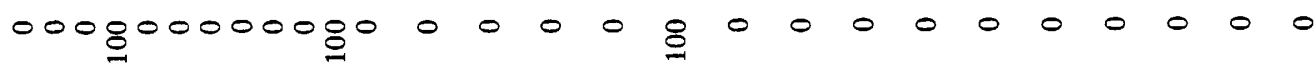

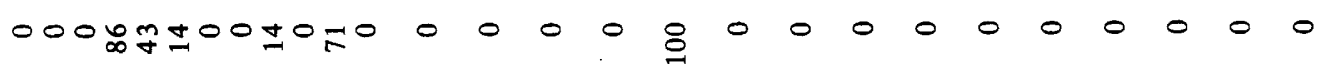

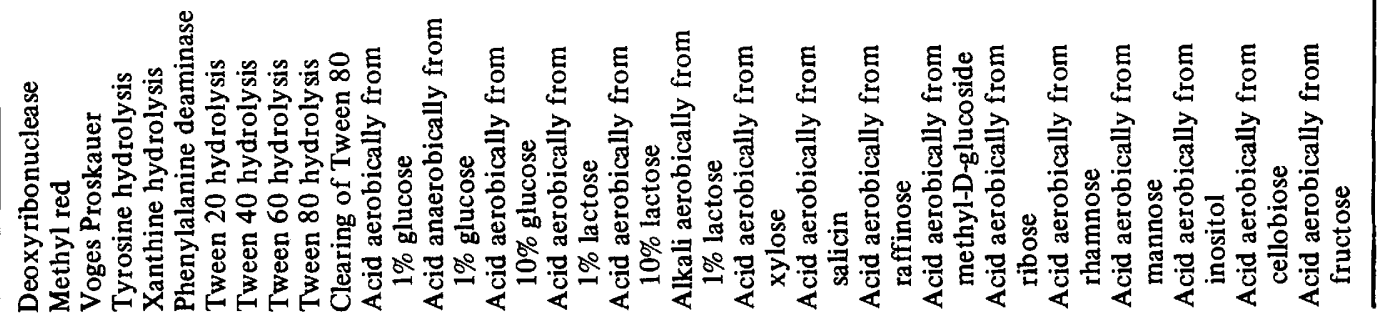




\begin{tabular}{|c|c|c|c|c|c|c|c|c|c|c|c|c|}
\hline 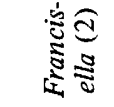 & $\bar{z}$ & $\tilde{z}$ & $\bar{z}$ & $\bar{z}$ & 乬 & $\tilde{z}$ & $\bar{z}$ & $\bar{z}$ & $\bar{z}$ & $\tilde{z}$ & $\stackrel{5}{\mathbf{z}}$ & \\
\hline 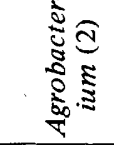 & 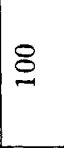 & 0 & 0 & $\stackrel{8}{ }$ & 0 & 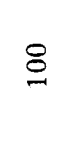 & 0 & 0 & 0 & 0 & in & \\
\hline 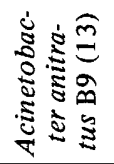 & $\infty$ & $\bar{m}$ & 0 & 8 & గ్ & $\infty$ & 0 & 0 & $\tilde{6}$ & 0 & 0 & \\
\hline 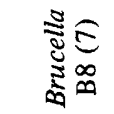 & $\stackrel{\xi}{z}$ & $\stackrel{5}{z}$ & $\hat{z}$ & $\tilde{z}$ & 乬 & $\vec{z}$ & $\tilde{z}$ & 5 & $\bar{z}$ & $\overline{\mathbf{z}}$ & $\bar{z}$ & \\
\hline 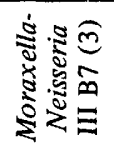 & 0 & 0 & 0 & 0 & 0 & 0 & 0 & 0 & 0 & 0 & 0 & \\
\hline 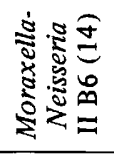 & 0 & ㄱ. & 0 & \pm & $\vec{\sim}$ & ते & $\vec{\sim}$ & \pm & શે & 0 & 0 & 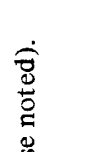 \\
\hline 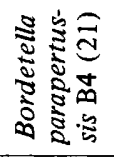 & 0 & 0 & 0 & 0 & 0 & 0 & 0 & 0 & 0 & 0 & 0 & 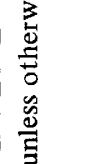 \\
\hline 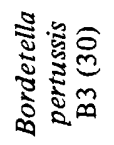 & 0 & 0 & 0 & 0 & 0 & 0 & 0 & 0 & 0 & 0 & 0 & 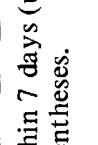 \\
\hline 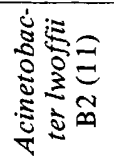 & 0 & 0 & 0 & 0 & 0 & 0 & 0 & 0 & 0 & 0 & 0 & 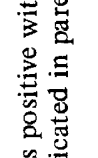 \\
\hline 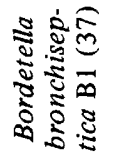 & 0 & 0 & 0 & 0 & 0 & 0 & 0 & 0 & 0 & 0 & 0 & 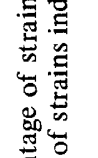 \\
\hline 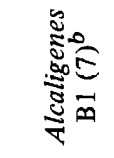 & 10 & 0 & 0 & 0 & 0 & 0 & 0 & 0 & 0 & 0 & 0 & 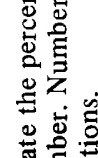 \\
\hline 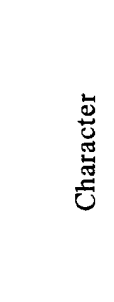 & 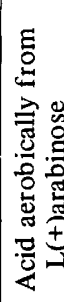 & 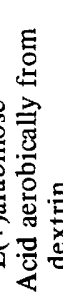 & 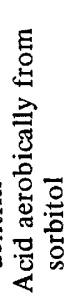 & 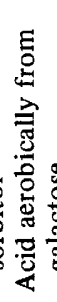 & 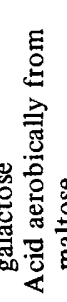 & 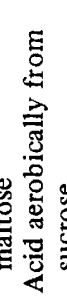 & 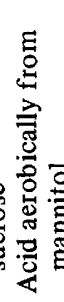 & 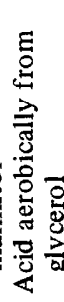 & 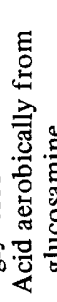 & 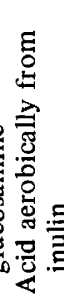 & 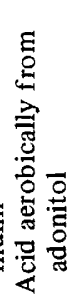 & 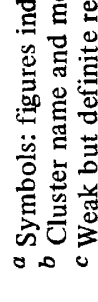 \\
\hline
\end{tabular}


allowance for factors such as growth rate, or length and temperature of incubation, that would otherwise contribute toward overall dissimilarity. $D_{P}$ (or its complement $S_{P}$ ) can be clustered like other similarity coefficients and is intended to give taxonomic relationships that are less subject to disturbance by general factors of the kind mentioned.

The mean, range, and standard deviation of vigor of the clusters of group B are shown in Table 5, based on all characters including carbohydrate tests. The lowest values are shown by Bordetella and the highest by Brucella, but the spread is not great. In consequence of the fairly uniform values of vigor, its removal did not greatly alter the resemblances, so that clustering on $D_{P}$ gave very similar results to Fig. 3. There were a few changes: the three clusters of Moraxella and Neisseria (B5, B6, and B7) were less distinct, so that these clusters appear to separate from each other in part because of vigor differences; some changes occurred in the composition of $\mathrm{B} 2$, and two strains of Brucella $\mathrm{J} 159$ and J161 were removed from cluster B8. It is worth noting that the four aberrant strains which appeared in group $\mathrm{A}$ in computation 2 had exceptionally high vigor (average 0.490 ). However, the pattern results did confirm that the difference between Acinetobacter lwoffii and $A$. anitratus was not simply accounted for by saying that $A$. anitratus is the metabolically active end of a spectrum containing both species, because the two clusters B2 and B9 remained separate in the $D_{P}$ phenogram.

\section{DISCUSSION}

The results of the study reported here throw doubt on the taxonomic validity of the family Brucellaceae as given at present in Bergey's Manual (13). Eight genera were listed there: Pasteurella, Bordetella, Brucella, Haemophilus, Actinobacillus, Calymmatobacterium, Morax- ella, and Noguchia. These have varied properties: some have a fermentative metabolism, others are oxidative, others do not attack carbohydrates. The range of $\mathrm{G} / \mathrm{C}$ ratio, 33 to $70 \%$ (36), is also evidence of heterogeneity. There is already much evidence (41) to support two changes that are gaining increasing acceptance. (i) The plague bacillus and its allies should be segregated from the other pasteurellas as a genus, Yersinia, that appears close to Enterobacteriaceae, and they may be best included in that family. (ii) The genus Moraxella is very closely allied to at least some species of Neisseria, so that it might be best transferred to Neisseriaceae (50), and Acinetobacter is best temporarily associated with that family for practical reasons.

Our findings, as well as providing support for (ii), also suggest another major change: (iii) the fermentative genera of group A, Actinobacillus, Pasteurella, and Haemophilus, should be separated from the others. The more detailed evidence for the third point is discussed elsewhere (72), but we may note here that these three genera are phenetically very similar, and their $\mathrm{G} / \mathrm{C}$ base ratios fall in the narrow range of 35 to $45 \%$ (36).

Although many neisserias and moraxellas are extremely similar phenetically, as noted in several reports as well as our own $(7,35,81)$, the present study affords no assistance on whether Moraxella and Neisseria should be united, because we did not include Neisseria gonorrhoeae, the type species of the latter genus. There is some evidence that Neisseria is notably heterogeneous (41), so the question may instead be whether species such as $N$. catarrhalis, $N$. caviae, and $N$. ovis should be transferred to Moraxella.

It is not yet clear whether Acinetobacter should be included in the Neisseriaceae. Acinetobacter species grow well on ordinary media and remain viable without subculture for quite long periods, whereas both Moraxella and

TABLE 5. Vigor values of the clusters of group $B$

\begin{tabular}{|c|c|c|c|}
\hline Cluster & Range & Mean & $\mathrm{SD}$ \\
\hline $\begin{array}{l}\text { B1 Alcaligenes faecalis-Bordetella } \\
\text { bronchiseptica }\end{array}$ & $0.353-0.424$ & 0.390 & 0.020 \\
\hline B2 Acinetobacter lwoffii & $0.325-0.406$ & 0.374 & 0.023 \\
\hline B3 Bordetella pertussis & $0.317-0.344$ & 0.330 & 0.011 \\
\hline B4 Bordetella parapertussis & $0.386-0.405$ & 0.398 & 0.005 \\
\hline B6 Moraxella-Neisseria II & $0.328-0.581$ & 0.436 & 0.060 \\
\hline B7 Moraxella-Neisseria III & $0.426-0.496$ & 0.465 & 0.036 \\
\hline B8 Brucella & $0.357-0.519$ & 0.466 & 0.052 \\
\hline B9 Acinetobacter anitratus & $0.408-0.504$ & 0.454 & 0.037 \\
\hline
\end{tabular}


Neisseria are much more fastidious and sensitive to aging. The $\mathrm{G} / \mathrm{C}$ base ratios are close to those of Moraxella and Neisseria, but Johnson, Anderson, and Ordal (40) found little evidence of nucleic acid hybridization between oxidasepositive moraxellas and oxidase-negative acinetobacters. They reached conclusions similar to Stenzel and Mannheim (77) and Baumann, Doudoroff, and Stanier (7) that the two should be kept separate. Recent genetic studies (42) support this. The reliability of the oxidase reaction for separating Moraxella and Acinetobacter is questioned by Juni (42) and also by Thornley (81), who found that many of her phenon 4 strains (equivalent to Acinetobacter lwoffii) were oxidase positive. Two out of nine strains of $A$. lwoffii studied by us were also oxidase positive, so it would seem that splitting the moraxellas and acinetobacters on the oxidase reaction may not be entirely satisfactory.

We recognize two species of Acinetobacter, $A$. lwoffii and $A$. anitratus, equivalent to clusters B2 and B9, respectively. They are well defined and reasonably distinct on both similarity and pattern coefficients. This is in agreement with results of previous studies ( 8 , $59,60,81)$. The pattern results show that the difference between these species is not simply one of metabolic activity. Nevertheless, transformation can occur between them (42), they are both rather diffuse groups, and it is possible that they overlap to a small extent, or that occasional intermediates occur. Strains of $A$. anitratus are almost always saccharolytic, and it is generally thought that $A$. lwoffii is nonsaccharolytic. Baumann, Doudoroff, and Stanier (8) found a few saccharolytic strains of the $A$. lwoffii type. Three of these were also studied by us (J26, J32, and J34), and although we found them to be nonsaccharolytic, evidence has recently been published (74) that some strains of $A$. lwoffii can produce acid from glucose in the ammonium salt sugar medium of Smith, Gordon, and Clark (67), although Henderson (34) had found that none of five strains of $A$. lwoffii he examined could do so on this medium. Using a modification of this medium (Johnson, unpublished data), in which bromothymol blue indicator was used to replace the less sensitive bromocresol purple, it was found that most strains of $A$. lwoffii will produce definite acid from glucose, xylose, arabinose, and ethanol; strains of $A$. anitratus produce acid from these sugars and, in addition, cellobiose, rhamnose, and lactose. Thus, even on this medium the two species can be separated, although $A$. lwoffii cannot now be regarded as strictly nonsaccharolytic. Baumann, Doudoroff, and Stanier (8) also had some strains similar to $A$. anitratus that were nonsaccharolytic; they formed a distinct group, however, and the only strain of this kind that we also studied, J41, did not fall into any cluster. There may be, therefore, at least one additional species of $A$ cinetobacter of which we had only a single representative. The position is, however, not entirely clear, because a few strains that in the present study fell into cluster B9 (J26, J31, J32, J34) were found by Baumann, Doudoroff, and Stanier to fall outside their group A (which contained $A$. anitratum and $A$. calcoaceticus).

Further evidence that other species may exist is provided by Acinetobacter calcoaceticus (J25). The Subcommittee on the Taxonomy of Moraxella and Allied Bacteria (50) suggests that this name should be the correct name for $A$. anitratus. We found that it was not a typical strain of $A$. anitratus, as it did not enter cluster B9 in either computation 2 or 3 , nor using pattern coefficients (showing that the atypicality is not due simply to loss variation). Neither was it typical of $A$, anitratus in the study of Baumann, Doudoroff, and Stanier (8). It may therefore be premature to regard these two as synonyms.

A cinetobacter lwoffii may be phenetically intermediate between Moraxella and Bordetella; indeed Steel and Cowan (76) placed $B$. parapertussis in the genus $A$ cinetobacter. There are difficulties in distinguishing between $B$. parapertussis and $A$. lwoffii, particularly if the strains of the latter produce an alkaline reaction in the Hugh and Leifson oxidation-fermentation medium. The high phenetic similarity between them is shown by an average intergroup similarity of $80.2 \%$. Only two clearly differential characters were found, the ability of $B$. parapertussis to produce a brown, diffusible pigment from tyrosine and to grow in the presence of the antibacterial compound $M$ and $B$ 938. However, $\mathrm{G} / \mathrm{C}$ base ratios were determined on six strains of $B$. parapertussis (Johnson, Ph.D. thesis, Univ, of Leicester England, 1972), and these varied from 67.7 to $70.0 \%$; this difference of about $25 \%$ from published values for $A$. lwoffii suggests that they should not be included within the same genus. The ratios found by Johnson for six strains of $B$. pertussis were almost the same, ranging from 67.0 to $69.8 \%$.

Another problem is the relationship between Alcaligenes and Bordetella bronchiseptica. In this study all strains of $A$. faecalis, one strain of A. riscosus and strains of $A$. denitrificans and 
$A$. odorans fell into the same cluster as $B$. bronchiseptica, with the strains of Alcaligenes having a higher average similarity to the strains of $B$. bronchiseptica than to each other. The only characters that differentiated them were tetrazolium reduction and growth on potassium tellurite agar (Table 4). The species of Alcaligenes included in this group are those which are motile and oxidase positive. This distinguishes them from the nonmotile, oxidase-negative strains which we believe are misidentified strains of Acinetobacter lwoffii.

There has been much confusion over the genus Alcaligenes and its type species, $A$. faecalis, the Bacillus faecalis alcaligenes of Petruschky (57). The original description of the genus by Castellani and Chalmers (16) was not very detailed. Petruschky's original description could apply equally well to $B$. bronchiseptica if the source of isolation was ignored. Hugh (Ph.D. thesis, Loyola University, Chicago, 1953) united peritrichous, nonsaccharolytic, gram-negative bacteria (such as Bordetella bronchiseptica, Alcaligenes faecalis, and A. denitrificans) to form his group I, and he agreed with an earlier report by Conn (17) that Petruschky's description was too vague to reidentify the organism. Many workers have found that urease production is the most useful test for differentiating $A$. faecalis from $B$. bronchiseptica, but in our study three out of seven strains of Alcaligenes were urease positive. Recently Pickett and Pedersen (58) found differences in the production of alkali from certain amides and organic salts, and these may prove useful after further evaluation. There is abundant evidence for retaining $B$. bronchiseptica in the same genus as $B$. pertussis and $B$. parapertussis on physiological, biochemical, serological, and genetic grounds $(20,28,46,64,66)$. The question is, therefore, whether Alcaligenes should be united with Bordetella. The generic name would be Alcaligenes for reason of priority. However, the genus-specific antigens of Bordetella and the species-specific antigens of $B$. bronchiseptica $(4,21,47)$ have not been identified in $A$. faecalis. For the present it seems wiser to keep the two genera separate.

The similarity between Bordetella and Brucella has been known for many years $(10,83)$. However, the genera also differ sharply in several ways: Brucella metabolizes alanine and DL-asparagine initially $(29,52)$, whereas glutamic acid and proline are the preferred amino acids for Bordetella (65). There have not been any reports of antigens shared by the two genera, and Hoyer and McCullough (38) found in deoxyribonucleic acid pairing studies that there was no detectable pairing between $B r u$ cella and Bordetella bronchiseptica.

The positions of two genera, Calymmatobacterium and Noguchia, still remain in doubt. We were unable to obtain any strains of Calymmatobacterium, and we have doubts on the authenticity of the only strain of Noguchia granulosis available.

There remain two problems of nomenclature. It is not clear who first legitimately published the specific epithet pertussis for the whoopingcough bacillus. Some have attributed the name to Bordet and Gengou (11), who originally isolated the organism, but they never used this specific epithet in any of their publications. Breed, Murray, and Smith (13) attributed the name to Holland (37), but this is incorrect because names listed by Holland are not validly published (39, Rule 12c). Buchanan, Holt, and Lessel (14) give two names for this organism which they state were validly published and are legitimate. The first was Bacillus tussis-convulsivae Affanassjew 1887. Affanassjew did not, however, isolate the whooping-cough bacillus. Koplik (43) isolated an organism which he considered identical to the one described by Affanassjew, yet it was motile and grew anaerobically. These are not properties of $B$. pertussis. Migula (53) described Bacillus pertussis, which he attributed to Affanassjew, but Migula's organism was able to grow on gelatin and also grew anaerobically. Clearly Bacillus tussis-convulsivae cannot be identified with the whooping-cough bacillus. The other name cited by Buchanan, Holt, and Lessel is Haemophilus pertussis Pribram 1933. Pribram mentions $H$. pertussis only in the list of strains maintained in the Vienna Microbiological Collection; the organism is attributed to Bordet 1906 and not, as it should have been, to Bordet and Gengou (11), and therefore it is not validly published (39, Rule 12c) and also lacks a description or a reference to an effectively published description. Ferry and Noble (25) used the name Bacterium pertussis for the whooping-cough bacillus. They did not attribute the organism to Bordet and Genou (11), neither did they indicate they were naming or renaming a bacterial species, so the validity of publication is dubious. Bergey et al. (9) published an avowed taxonomic description of an organism, Haemophilus pertussis (Bordet and Gengou) Committee, Society of American Bacteriologists, which is clearly the whooping-cough bacillus. Although they incorrectly attribute the epithet to Bordet and Gengou, this name appears undoubtedly valid and has priority over that of Pribram. We therefore take the view 
that the correct name for the whooping-cough bacillus is Bordetella pertussis (Bergey et al. 1923) Moreno-López 1952.

The second problem is the correct name for Bordetella bronchiseptica. This organism was originally isolated from dogs by Ferry (22) and named Bacillus bronchicanis (23). In a later paper, Ferry (24) changed the specific epithet to bronchiseptica because the organism was able to produce disease in other animals besides dogs. Under Rule 23 of the International Code of Nomenclature of Bacteria (39), a name cannot be changed because it is inappropriate, so that the correct epithet remains bronchicanis. This epithet has been used by few authors since, except Haupt (33). The epithet bronchiseptica is almost universally used; to change it back to bronchicanis would cause much confusion, and it would seem better to conserve the well-known one.

The taxonomy of the Brucellaceae would, in our opinion, be improved by reducing the genera to three, Brucella, Bcrdetella and Alcaligenes. The fermentative genera Haemophilus, Pasteurella, and Actinobacillus should be removed and could form the basis of a separate family. The three genera that would remain are phenotypically very similar. They have a marked preference for metabolizing amino acids $(29,52,66)$. Two genera show a requirement for accessory growth factors: Bordetella requires nicotinamide and Brucella requires thiamine. Morphologically, they are all aerobic, gram-negative coccobacilli that show little tendency towards pleomorphism. They are usually oxidase positive, although Bordetella parapertussis is an exception. Finally, all have high $\mathrm{G} / \mathrm{C}$ base ratios, usually above $55 \%$. The position of Francisella is uncertain and requires further study.

The members of Brucellaceae have the reputation of being difficult to study, but we believe they are not particularly difficult provided the bacteriologist spends some time devising suitable culture media and standardizing test conditions. There is still a need to develop new biochemical tests. Bordetella, Alcaligenes, Brucella, and Acinetobacter give a large number of negative results in currently used identification tests, so the development of new tests, and perhaps the inclusion of carbon and nitrogen utilizations, should prove valuable for future work.

\section{ACKNOWLEDGMENTS}

The work reported was done during the tenure by one of us (R.J.) of a Scholarship from the Medical
Research Council of Great Britain. The assistance of M. J. Sackin with computing is also gratefully acknowledged.

\section{REPRINT REQUESTS}

Address requests for reprints to: Dr. P.H.A. Sneath, Medical Research Council, Microbial Systematics Unit, University of Leicester, University Road, Leicester, England.

\section{LITERATURE CITED}

1. Affanassjew, M. J. 1887. Aetiologie und klinische Bakteriologie der Keuchhustens. St. Petersb. Med. Wschr. 12:323, 331, 339, 347.

2. American Type Culture Collection. 1970. Catalogue of strains, 9th ed. American Type Culture Collection, Rockville, Maryland.

3. American Type Culture Collection. 1972. Catalogue of strains, 10th ed. American Type Culture Collection, Rockville, Maryland.

4. Andersen, E. K. 1953. Serological studies on $H$. pertussis, $H$. parapertussis, and $H$. bronchisepticus. Acta Pathol. Microbiol. Scand. 33:202-224.

5. Audureau, A. 1940. Étude du genre Moraxella. Ann. Inst. Pasteur 64:126-166.

6. Bacon, M. F., W. G. Overend, P. H. Lloyd, and A. R. Peacocke. 1967. The isolation, composition and physiological properties of DNA from $B$. pertussis. Arch. Biochem. Biophys. 118:352-361.

7. Baumann, P., M. Doudoroff, and R. Y. Stanier. 1968a. A study of the Moraxella group. I. The genus Moraxella and the Neisseria catarrhalis group. J. Bacteriol. 95:58-73.

8. Baumann, P., M. Doudoroff, and R. Y. Stanier. 1968b. A study of the Moraxella group. II. Oxidative-negative species (genus Acinetobacter). J. Bacteriol. 95:1520-1541.

9. Bergey, D. H., F. C. Harrison, R. S. Breed, B. W. Hammer, and F. M. Huntoon. 1923. Bergey's manual of determinative bacteriology, 1st. ed. The Williams and Wilkins Co., Baltimore.

10. Bergey, D. H., F. C. Harrison, R. S. Breed, B. W. Hammer, and F. M. Huntoon. 1925. Bergey's manual of determinative bacteriology, 2nd. ed. The Williams and Wilkins Co., Baltimore.

11. Bordet, J., and O. Gengou. 1906. Le microbe de la coqueluche. Ann. Inst. Pasteur 20:731-741.

12. Breed, R. S., E. G. D. Murray, and A. P. Hitchens. 1948. Bergey's manual of determinative bacteriology, 6th. ed. The Williams and Wilkins Co., Baltimore.

13. Breed, R. S., E. G. D. Murray, and N. R. Smith. 1957. Bergey's manual of determinative bacteriology, 7th. ed. The Williams and Wilkins Co., Baltimore.

14. Buchanan, R. E., J. G. Holt, and E. F. Lessel, Jr. 1966. Index Bergeyana. The Williams and Wilkins Co., Baltimore.

15. Butler, O. L. 1962. A defined medium for Haemophilus influenzae and Haemophilus parainfluenzae. J. Gen. Microbiol. 27:51-60. 
16. Castellani, A., and A. J. Chalmers. 1919. Manual of tropical medicine, 3rd. ed. William Wood and Co., New York.

17. Conn, H. J. 1942. Validity of the genus Alcaligenes. J. Bacteriol. 44:353-360.

18. Craigie, J. 1931. Studies on the serological reactions of the flagella of $B$. typhosus. $\mathbf{J}$. Immunol. 21:417-511.

19. Cruickshank, R. 1965. Medical microbiology. E. and S. Livingstone, Ltd., Edinburgh.

20. De Ley, J. 1968. DNA base composition and taxonomy of some Acinetobacter strains. Antonie van Leeuwenhoek J. Microbiol. Serol. 34:109-114.

21. Eldering, G., C. Hornbeck, and J. Baker. 1957. Serological study of Bordetella pertussis and related species. J. Bacteriol. 74:133-136.

22. Ferry, N. S. 1910. A preliminary report of the bacterial findings in canine distemper. Amer. Vet. Rev. 37:499-504.

23. Ferry, N. S. 1911. Etiology of canine distemper. J. Infect. Dis. 8:399-420.

24. Ferry, N. S. 1912. Further studies on the Bacillus bronchicanis, the cause of canine distemper. Amer. Vet. Rev. 41:77-79.

25. Ferry, N. S., and A. Noble. 1918. Studies relative to the apparent close relationship between Bact. pertussis and $B$. bronchisepticus I. Cultural agglutination and absorption reactions. J. Bacteriol. 3:193-208

26. Fewson, C. A. 1967a. The growth and metabolic versatility of the Gram-negative bacterium NCIB 8250 ("Vibrio O 1"). J. Gen. Microbiol. 46:255-266.

27. Fewson, C. A. 1967b. The identity of the Gram-negative bacterium NCIB 8250 ("Vibrio O 1"). J. Gen. Microbiol. 48:107-110.

28. Fukumi, H., E. Sayama, J. Tomizawa, and T. Uchida. 1953. Nutritional requirements and respiratory pattern of pertussis-parapertussis-bronchisepticus group of micro-organisms. Jap. J. Med. Sci. Biol. 6:587-601.

29. Gerhardt, P., and I. B. Wilson. 1948. The nutrition of brucellae: growth in simple chemically defined media. J. Bacteriol. 56:17-24.

30. Gordon, R. E., and M. M. Smith. 1955. Rapidly growing, acid fast bacteria. II. Species description of Mycobacterium fortuitum Cruz. J. Bacteriol. 69:502-507.

31. Gottlieb, D. 1961. An evaluation of criteria and procedures used in the description and characterization of the streptomycetes. A cooperative study. Appl. Microbiol. 9:55-65.

32. Gower, J. C. 1971. A general coefficient of similarity and some of its properties. Biometrics 27:857-871.

33. Haupt, H. 1935. Zur Systematik der Bakterien. Die für Mensch und Tier pathogenen gramnegativen alkali-bildenden Stäbchenbakterien (Aerobactereae Pribram 1929 em.). Ergeb. Hyg. Bakteriol. 17:175-300.

34. Henderson, A. 1967. The saccharolytic activity of Acinetobacter lwoffii and A. anitratus. J. Gen. Microbiol. 49:487-489.

35. Henriksen, S. D., and K. B $\phi$ vre. 1968. The taxonomy of the genera Moraxella and Neisseria. J. Gen. Microbiol. 51:387-392.

36. Hill, L. R. 1966. An index to deoxyribonucleic acid base compositions of bacterial species. J. Gen. Microbiol. 44:419-427.

37. Holland, D. 1920. Generic index of the commoner forms of bacteria. J. Bacteriol. 5:215-229.

38. Hoyer, B. H., and N. B. McCullough. 1968. Homologies of deoxyribonucleic acids from Brucella ovis, canine abortion organisms, and other Brucella species. J. Bacteriol. 96:1783-1790.

39. International Code of Nomenclature of Bacteria. 1966. Int. J. Syst. Bacteriol. 16:459-490.

40. Johnson, J. L., R. S. Anderson, and E. J. Ordal. 1970. Nucleic acid homologies among oxidasenegative Moraxella species. J. Bacteriol. 101:568-573.

41. Jones, D., and P. H. A. Sneath. 1970. Genetic transfer and bacterial taxonomy. Bacteriol. Rev. 34:40-81.

42. Juni, E. 1972. Interspecies transformation of Acinetobacter: genetic evidence for a ubiquitous genus. J. Bacteriol. 112:917-931.

43. Koplik, H. 1897. The bacteriology of pertussis. Brit. Med. J. ii: 1051.

44. Kovács, N. 1956. Identification of Pseudomonas pyocyanea by the oxidase reaction. Nature (London) 178:703.

45. Kuwajima, Y., T. Matsui, and M. Kishigami. 1957. The growth-supporting effect of some anion exchange resins for phase I Haemophilus pertussis. Jap. J. Microbiol. 1:375-381.

46. Lacey, B. W. 1953. On the serology and taxonomy of Haemophilus pertussis, parapertussis and bronchisepticus. Atti del VI congresso Internazionale di Microbiologia 1:sez.vi-vii, 526-527.

47. Lacey, B. W. 1960. Antigenic modulation of Bordetella pertussis. J. Hyg. 58:57-93.

48. Lapage, S. P., S. Bascomb, W. R. Willcox, and M. A. Curtis. 1970. Computer identification of bacteria, p. 1-22. In A. Baillie and R. J. Gilbert (ed.), Automation, mechanization and data handling in microbiology. Academic Press Inc., London.

49. Lautrop, H. 1960. Laboratory diagnosis of whooping cough or Bordetella infections. Bull. W.H.O. 23:15-35.

50. Lessel, E. F. 1971. International committee on systematic bacteriology. Subcommittee on the taxonomy of Moraxella and allied bacteria. Int. J. Syst. Bacteriol. 21:213-214.

51. Liston, J., W. Weibe, and R. R. Colwell. 1963. Quantitative approach to the study of bacterial species. J. Bacteriol. 85:1061-1070.

52. Meyer, M. E., and H. S. Cameron. 1958. Species metabolic patterns within the genus Brucella. Amer. J. Vet. Res. 19:754-758.

53. Migula, W. 1900. System der Bakterien, vol. 2. Gustav Fischer, Jena.

54. Moreno-López, M. 1952. El genero Bordetella. Microbiol. Espanol. 5:177-181.

55. Noguchi, H. 1928. The etiology of trachoma. I. Pathological, bacteriological and direct inoculation investigations of the trachoma prevailing 
among American Indians. J. Exp. Med. (suppl. 2) 48:1-22.

56. Olitsky, P. K., J. T. Syverton, and J. R. Tyler. 1934. Studies on the etiology of spontaneous conjunctival folliculosis of rabbits. J. Exp. Med. 60:375-384.

57. Petruschky, J. 1896. Bacillus faecalis alcaligenes (n. sp.). Zentralbl. Bakteriol. Parasitenk. Infektionskr. Hyg. Abt. 1 19:187-191.

58. Pickett, M. J., and M. M. Pedersen. 1970. Salient features of nonsaccharolytic and weakly saccharolytic nonfermentative rods. Can. J. Microbiol. 16:401 409 .

59. Pintér, M., and I. Bende. 1967. Computer analysis of Acinetobacter lwoffii (Moraxella lwoffii) and Acinetobacter anitratus (Moraxella glucidolytica) strains. J. Gen. Microbiol. 46:267-272.

60. Pintér, M., and I. Bende. 1968. Biochemical similarity of Acinetobacter lwoffii and Acinetobacter anitratus. Pathol. Microbiol. 31:41-50.

61. Pribram, E. 1933. Klassification der Schizomyceten. F. Deuticke, Leipzig.

62. Public Health Laboratory Services Board 1972. Catalogue of the National Collection of Type Cultures. Her Majesty's Stationery Office, London.

63. Rahn, O. 1937. New principles for the classification of bacteria. Zentralbl. Bakteriol. Parasitenk. Infektionskr. Hyg. Abt. 2 96:273-286.

64. Rauch, H. C., and M. J. Pickett. 1961. Bordetella bronchiseptica bacteriophage. Can. J. Microbiol. 7:125-134

65. Rowatt, E. 1953. Amino acid metabolism in the genus Bordetella. J. Gen. Microbiol. 13:552-560.

66. Rowatt, E. 1957. The growth of Bordetella pertussis: a review. J. Gen. Microbiol. 17:297-326.

67. Smith, N. R., R. E. Gordon, and F. E. Clark. 1952. Aerobic sporeforming bacteria. Agriculture monograph no. 16. U.S. Dept. Agriculture, Washington, D.C.

68. Sneath, P. H. A. 1966. Identification methods applied to Chromobacterium, p. 15-20. In B. M. Gibbs and F. A. Skinner (ed.), Identification methods for microbiologists, part A. Academic Press Inc., London.

69. Sneath, P. H. A. 1968. Vigour and pattern in taxonomy. J. Gen. Microbiol. 54:1-11.

70. Sneath, P. H. A. 1972. Computer taxonomy, p. 29-98. In J. R. Norris and D. W. Ribbons (ed.), Methods in microbiology, vol. 7A. Academic Press
Inc., London.

71. Sneath, P. H. A., and R. Johnson. 1972. The influence on numerical taxonomic similarities of errors in microbiological tests. J. Gen. Microbiol. 72:377-392.

72. Sneath, P. H. A., and R. Johnson. 1973 Numerical taxonomy of Haemophilus and related bacteria. Int. J. Syst. Bacteriol. 23:405-418.

73. Sneath, P. H. A., and V. B. D. Skerman. 1966. A list of type and reference strains of bacteria. Int. J. Syst. Bacteriol. 16:1-134.

74. Snell, J. J. S., and S. P. Lapage. 1971. Comparison of four methods for demonstrating. glucose breakdown by bacteria. J. Gen. Microbiol. 68:221-225.

75. Sokal, R. R., and P. H. A. Sneath. 1963. Principles of numerical tax onomy. W. H. Freeman and Co., San Francisco.

76. Steel, K. J., and S. T. Cowan. 1964. Le rattachement de Bacterium anitratum, Moraxella lwoffi, Bacillus mallei et Haemophilus parapertussis au genre Acinetobacter Brisou et Prévot. Ann. Inst. Pasteur 106:479-483.

77. Stenzel, W., and W. Mannheim. 1963. On the classification of some non-motile and coccoid diplobacteria exhibiting the properties of Achromobacteriaceae. Int. Bull. Bacteriol. Nomencl. Taxon. 13:195-200.

78. Sutherland, I. W., and J. F. Wilkinson. 1961. A new growth medium for virulent Bordetella pertussis. J. Pathol. Bacteriol. 82:431-438.

79. Taylor, G. R., R. K. Guthrie, and E. B. Shirling. 1970. Serological characteristics of Streptomyces species using cell wall immunizing antigens. Can. J. Microbiol. 16:107-115.

80. Thornley, M. J. 1960. The differentiation of Pseudomonas from other Gram-negative bacteria on the basis of arginine metabolism. J. Appl. Bacteriol. 23:37-52.

81. Thornley, M. J. 1967. A taxonomic study of Acinetobacter and related genera. J. Gen. Microbiol. 49:211-257.

82. Tilden, E. B., and J. R. Tyler. 1930. Bacterium granulosis in relation to trachoma: its recovery from experimentally infected monkeys and from human trachoma. J. Exp. Med. 52:617-635.

83. Topley, W. W. C., and G. S. Wilson. 1929. The principles of bacteriology and immunity, 1 st ed. Edward Arnold and Co., London.

84. Wilson, G. S., and A. A. Miles. 1961. Topley and Wilson's principles of bacteriology and immunity, 4th ed. Edward Arnold and Co., London. 